\title{
Micro-uncertainty and growth
}

Citation for published version (APA):

Straathof, S. M. (2002). Micro-uncertainty and growth. UNU-MERIT, Maastricht Economic and Social Research and Training Centre on Innovation and Technology. MERIT-Infonomics Research Memorandum Series No. 001 https://doi.org/10.26481/umamer.2002001

Document status and date:

Published: 01/01/2002

DOI:

10.26481/umamer.2002001

Document Version:

Publisher's PDF, also known as Version of record

\section{Please check the document version of this publication:}

- A submitted manuscript is the version of the article upon submission and before peer-review. There can be important differences between the submitted version and the official published version of record.

People interested in the research are advised to contact the author for the final version of the publication, or visit the DOI to the publisher's website.

- The final author version and the galley proof are versions of the publication after peer review.

- The final published version features the final layout of the paper including the volume, issue and page numbers.

Link to publication

\footnotetext{
General rights rights.

- You may freely distribute the URL identifying the publication in the public portal. please follow below link for the End User Agreement:

www.umlib.nl/taverne-license

Take down policy

If you believe that this document breaches copyright please contact us at:

repository@maastrichtuniversity.nl

providing details and we will investigate your claim.
}

Copyright and moral rights for the publications made accessible in the public portal are retained by the authors and/or other copyright owners and it is a condition of accessing publications that users recognise and abide by the legal requirements associated with these

- Users may download and print one copy of any publication from the public portal for the purpose of private study or research.

- You may not further distribute the material or use it for any profit-making activity or commercial gain

If the publication is distributed under the terms of Article $25 \mathrm{fa}$ of the Dutch Copyright Act, indicated by the "Taverne" license above, 


\section{MERIT-Infonomics Research Memorandum series}

\section{Micro-uncertainty and growth}

2002-001

\section{Bas Straathof}

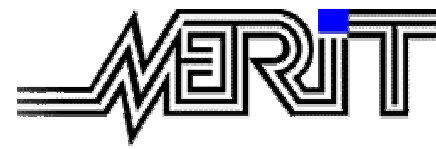

MERIT - Maastricht Economic Research Institute on Innovation and Technology PO Box 616

6200 MD Maastricht

The Netherlands

$\mathrm{T}:+31433883875$

F: +31433884905

http://meritbbs.unimaas.nl

e-mail:secr-merit@merit.unimaas.nl

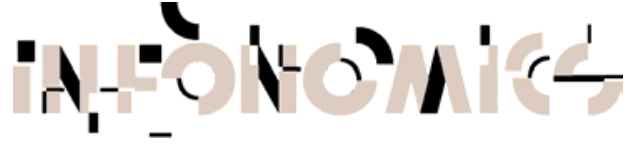

International Institute of Infonomics

PO Box 2606

6401 DC Heerlen

The Netherlands

T: +31455707690

F: +3145 5706262

http://www.infonomics.nl

e-mail: secr@infonomics.nl 


\title{
Micro-uncertainty and growth ${ }^{\text {}}$
}

\author{
Bas Straathof
}

January, 2002

Abstract:

In this paper idiosyncratic uncertainty is introduced in a model of economic growth with an increasing variety of intermediate products. Both the costs of producing intermediate products and their quality are uncertain for all producers at all times. Using the property of the model that the number of intermediate firms is infinite, uncertainty cancels out in the aggregate. Furthermore, the magnitude of uncertainty has several deterministic effects on long-term economic growth. First, uncertainty causes growth in the heterogeneity of intermediate firms. As heterogeneity grows, the number of very efficient intermediate firms increases. Depending on the degree of competition and the returns to intermediate products, these firms can attract an increasing share of demand by the final sector. This makes final production become more efficient over time. Second, uncertainty changes the rate at which new intermediates are introduced by its effect on the efficiency of final production and by a real-option effect.

Keywords: Increasing variety, idiosyncratic uncertainty JEL classification: O41, D81, L11

\footnotetext{
* I would like to thank Lex Borghans, Fulvio Castellacci, Michael Funke, Peter Howitt, Mark Sanders, Bas ter Weel, and Adriaan van Zon for their comments. Also, I would like to thank the participants of a MERIT seminar and the Zeuthen workshop 2001 in Copenhagen for their remarks.

$\dagger$ MERIT - Maastricht University, P.O. Box 616 - 6200 MD Maastricht - The Netherlands, tel. +31 43 3883879, b.straathof@merit.unimaas.nl.
} 


\section{Introduction}

Uncertainty plays an important part in many types of decisions, trivial or not, in probably every firm and household. It is therefore somewhat surprising that the study of the relations between uncertainty and economic growth has been limited to the domain of household saving behavior. The implications of uncertainty for the performance of firms have largely been ignored in the growth literature (see section 2). This paper attempts to fill this gap by combining two basic ideas - namely that uncertainty both creates opportunities and makes people reluctant to decide - in a model of economic growth.

In this paper uncertainty is introduced in a model with increasing variety of intermediate products that is similar to that of Romer (1990). The model consists of three sectors of production. First, the consumption goods sector uses human capital, raw labor, and intermediates. Second, intermediate goods are produced with physical capital. Third, the research sector produces designs for new types of intermediate goods, also with the use of human capital. The efficiency of the research sector depends on the level of knowledge, which is equivalent to the number of intermediates. Consumers are assumed to spread their consumption evenly over time (Ramsey consumers). Long-term growth is made possible because of constant returns to the production of new designs.

Idiosyncratic uncertainty is introduced at the firm-level in the intermediate sector. Both the costs and quality of intermediate products are made uncertain for all producers at all times. In the model all distributions are known in advance and no subjective probability effects are present. Furthermore, uncertainty is measured by the variance in the change of the quality and cost parameters. This makes forecasts over a long period less precise than forecasts regarding the immediate future. Also, the variance of the levels of these parameters across firms is expected to grow over time.

How does the introduction of uncertainty affect the model? The intermediate sector is characterized by monopolistic competition. Suppose that, in case of certainty, all intermediate producers are equally efficient and equally profitable. They all have the same costs of production, and they all can sell the same amount of goods at identical prices. The introduction of firm-level uncertainty in quality and costs necessarily breaks down this symmetry as different firms have different fortunes. 'Lucky' firms are (temporarily) able to produce better products at lower costs, while 'unlucky' firms (temporarily) produce inferior products at high costs. This makes the final goods sector to shift its demand for intermediates from 'unlucky' firms to 'lucky' firms. By doing so, the final goods sector can increase its output above the maximum level attainable without uncertainty. The size of this substitution-effect naturally depends on the degree of competition between intermediate producers.

Uncertainty, however, also may reduce the efficiency of final output production. Because of diminishing returns to intermediate inputs, an increase in the quality (decrease in marginal costs) of an intermediate leads to a smaller absolute change in the demand for the intermediate than a decrease in quality (increase in marginal costs) of the same size does. Final output is a concave function of intermediate inputs and therefore, by Jensen's Inequality, the expected level of final production is negatively related with uncertainty (see appendix C on Jensen's Inequality). The relation between output and intermediate uncertainty depends on which effect is larger, the substitution-effect or the diminishing returns to intermediates effect. 
This does not explain why uncertainty might affect long-term growth. Rather it seems to point at a relation between uncertainty and the level of final output. As the level of uncertainty is approximated by the variance of the changes in quality or costs, the presence of uncertainty makes the differences between firms grow over time. Thus, although the variance of the changes in quality or costs is constant, the variance of quality and cost characteristics across firms does grow over time. This makes both the substitution-effect and the diminishing returns effect grow over time. If the substitution-effect is larger than the diminishing returns effect, then the growth rate of output depends positively on the level of intermediate uncertainty. In the model presented here, the number of intermediate firms is infinite. This property ensures that neither uncertainty in quality nor costs will lead to uncertainty in the aggregate.

Uncertainty in the intermediate sector does not only affect final output, it also has consequences for the research sector. The price of a new design for an intermediate product depends on the profits that the production of the intermediate is expected to generate. Uncertainty in quality and costs makes these profits uncertain as well. For the entrepreneur that wishes to set up a new intermediate firm, the purchase of a design is an irreversible investment with uncertain returns. Therefore, the entrepreneur will tend to wait before she purchases a new design as valuable information becomes available over time. Uncertainty increases the value of waiting when decisions are costly to reverse. This is known as the real-option effect (e.g. Dixit and Pindyck 1994).

Postponement, however, is not efficient for the research sector. Under some assumptions about the structure of the market for designs, the price of a design in the presence of uncertainty will be deterministic and will be less than the discounted sum of expected profits. Whether or not an increase in uncertainty will make the price of designs to rise or to fall depends on whether the decrease in the price due to the real-option effect is larger than the (possible) increase in the price induced by higher expected profits caused by more uncertainty. If the real-option effect is dominant, then the low price for designs reduces the wage rate of human capital in the research sector and leads to a shift of human capital from the research sector to the final goods sector. Long-term growth will in this case be lower when uncertainty increases as less resources are devoted to knowledge accumulation.

The overall impact of uncertainty on growth will depend on which of the discussed effects will be the strongest. If the substitution effect dominates the diminishing returns to intermediate inputs effect then growth is stimulated through continuing improvements in the efficiency of final production. The corresponding rise in expected profits will further stimulate growth through its encouragement of the introduction of new intermediates. On the other hand, the real-option effect slows down growth through its depressing effect on the introduction of new intermediate products. As opposed to the situation under certainty, the growth of the number of intermediate firms is not the sole engine of economic growth after the introduction of uncertainty.

The paper is organized as follows. Section 2 contains a brief survey of the theoretical literature on uncertainty and economic growth. Section 3 gives an overview of the most relevant empirical publications. In section 4, a model of endogenous growth with micro-uncertainty is presented. Section 5 deals with the long-term effects of uncertainty on growth. An interpretation of the results can be found in section 6 . Section 7 briefly discusses how the findings may relate to economic policy. The paper ends with some concluding remarks. 


\section{Theoretical literature}

Does uncertainty affect economic growth, or not? In order to answer this question, the literature on economic growth has primarily focussed on how uncertainty affects savings. Mirman (1971, p.179) observes that

(...) two divergent forces are at work. The first is the desire to consume more initially as a hedge against the uncertain future. The second force is the desire to consume less initially so as to increase the future consumption prospects.

Early contributions on savings and uncertainty are Phelps (1962), Levhari and Srinivasan (1969), and Rothschild and Stiglitz (1971). A change in savings has an impact on (short-term) economic growth. Brock and Mirman (1972) were the first to publish a model of economic growth under uncertainty. ${ }^{1}$

Most models that aim to explain the implications of uncertainty for long-term economic growth also rely on the effect of uncertainty on savings. Jones, Manuelli, and Stacchetti (1999) find a small positive relation between uncertainty and growth using a simulation model. De Hek (1999) introduces uncertainty into the endogenous growth models of Lucas (1988) and Romer (1986). In the first case, he finds that as uncertainty in the productivity of knowledge creation makes people less willing to invest in knowledge creation, long-term growth is negatively affected by uncertainty.

In the case of Romer (1986), De Hek shows that the effect of uncertainty on growth depends on the elasticity of marginal utility with respect to time. Precautionary savings lead to a higher investment rate, while 'hedging' reduces the rate of investment. The Solow-Swan model suggests that the savings rate does not affect the growth rate. Romer, however, links knowledge to capital accumulation. As a result, savings do have an effect on long-term growth.

All these studies were concerned with the effects of disturbances in aggregate variables on savings and growth. An exception to this pattern is Bertola (1994). He presents an endogenous growth model with firm-level uncertainty that does not rely on a savings-effect. Instead, uncertainty reduces the returns to investment because it is costly for firms to adjust their workforce.

In Schumpeterian theories of growth, uncertainty and growth are usually not related directly. Rather, uncertainty and growth are both the result of innovation and consequentially they will occur simultaneously. Grossman and Helpman (1991) presented a quality-ladder model where stochastic quality improvements at the level of the firm result in a constant aggregate growth rate. Aghion and Howitt (1992) propose a model of creative destruction with uncertainty in aggregate growth rates.

Another strand of literature focussed on the relation between uncertainty and economic development. Greenwood and Jovanovic (1990) argued that development of the financial sector increases the possibilities for diversification and encourages economic growth by reducing the costs of investing. As economies develop they become more stable. Acemoglu and Zilibotti

\footnotetext{
${ }^{1}$ They refer to an unpublished paper by J.A. Mirrlees, titled: 'Optimum allocation under uncertainty' from 1965 as being the first paper on this subject.
} 
(1997) emphasize that the number of activities of a (closed) economy tends to grow with development. They also arrive at the result that development fosters stability and vice versa.

In all of the literature mentioned above (with the exception of Bertola 1994), micro-uncertainty is not considered to be important as long as it does not cause disturbances in aggregate variables. The model presented in this paper is about an economy that is already at the stage of full diversification. However, uncertainty at the micro-level is shown to be still relevant to long-term growth. Diminishing returns to capital, imperfect competition, and irreversible investments all have implications for the relation between uncertainty and growth.

\section{Empirical literature}

I am not aware of any empirical studies on the relation between micro-uncertainty and growth. The literature on aggregate volatility and growth has to be used as a substitute. In any economy that is not fully diversified, micro-level volatility will work through in the aggregate. Studies on aggregate volatility therefore might seriously underestimate how growth is related to volatility.

In the first publications on the subject (a cross-section study by Kormendi and Meguire (1985) and pooled estimation by Grier and Tullock (1989)) it was concluded that growth and volatility are positively related. Using more sophisticated methods and panel data, Ramey and Ramey (1995) find a negative relation in both the full sample and the OECD sub-sample. Using similar methods, Aizenman and Marion (1999) find a negative relation for developing countries. Caporale and McKiernan $(1996,1998)$ find that growth is positively related to volatility. They used ARCH estimation on time series from the United States and the United Kingdom.

A more subtle, and probably more informative, approach is to consider the relation between investment and volatility. Ramey and Ramey (1995) do not find a relation between total aggregate investment and volatility. This result is confirmed by Aizenman and Marion (1999). However, Aizenman and Marion also find that private investment is clearly negatively related to volatility, whereas government investment is slightly positively related to volatility.

This confirms the results from micro-level and sectorial studies. The negative relation between irreversible investment that is predicted by real-option theory (see for example Dixit and Pindyck 1994) is supported by the majority of empirical studies conducted with sectorial and firm-level data (for a survey see Carruth, Dickerson, and Henley 2000). In particular, Goel and Ram (2001) find that the relation between expenditure on $R \& D$ and volatility is more negative than that between ordinary investment and volatility.

Given the dominant role of uncertainty in many decision making processes in many firms, it is surprising that empirical studies do not find major implications of uncertainty for economic growth. The model in this paper suggests that this might be due to effects that work in opposite directions.

\section{A model of growth with micro-uncertainty}

Uncertainty is introduced both in the quality of intermediate products and in the costs of producing them. The demand for intermediate products comes from the final goods sector. 
The production function of the final goods sector is given by

$$
Y=H_{Y}^{1-\alpha-\beta} L^{\beta} \int_{0}^{A}\left(\theta_{i} x_{i}\right)^{\alpha} \mathrm{d} i
$$

Here, $Y$ represents the output of the final goods sector, $H_{Y}$ is the amount of human capital used for the production of final goods, $L$ is unskilled labor, $x_{i}(i \in A)$ is the quantity of intermediate good $i$ that is used for the production of $Y, \theta_{i}$ is its quality, and $A$ is the number of intermediates.

The quality parameter, $\theta_{i}$, is a stochastic variable that is specific to each intermediate product and that changes over time. This variable is assumed to follow a geometric Brownian motion of the form

$$
\begin{aligned}
\theta_{i T} & =\exp \left[\ln \theta_{i 0}+\int_{0}^{T} \mathrm{~d} \ln \theta_{i t}\right] \\
\mathrm{d} \ln \theta_{i t} & =\left[\left(m_{\theta}-\frac{1}{2} \sigma_{\theta}^{2}\right) \mathrm{d} t+\sigma_{\theta} \mathrm{d} z_{\theta, i t}\right] \\
\mathrm{d} z_{\theta, i t} & =\epsilon_{\theta, i t} \sqrt{\mathrm{d} t} .
\end{aligned}
$$

Here, $m_{\theta}-\frac{1}{2} \sigma_{\theta}^{2}$ is the drift rate of the process, $\mathrm{d} t$ is a small increment in time, $\sigma_{\theta}^{2}$ is the variance of $\mathrm{d} \ln \theta, z_{\theta, i t}$ is a Wiener process, and $\epsilon_{\theta, i t}$ is a normally distributed random variable with mean zero and variance unity.

It is more convenient to work with changes in $\theta$ in stead of $\ln \theta$. Applying Itô's lemma to $\mathrm{d} \theta=\mathrm{d}(\exp [\ln \theta])$ gives

$$
\begin{aligned}
\mathrm{d} \theta & =\frac{\partial \exp [\ln \theta]}{\partial \ln \theta} \mathrm{d} \ln \theta+\frac{1}{2} \frac{\partial^{2} \exp [\ln \theta]}{\partial(\ln \theta)^{2}}(\mathrm{~d} \ln \theta)^{2} \\
& =\theta \mathrm{d} \ln \theta+\frac{1}{2} \theta(\mathrm{d} \ln \theta)^{2} \\
& =\theta\left(m_{\theta}-\frac{1}{2} \sigma_{\theta}^{2}\right) \mathrm{d} t+\theta \sigma_{\theta} \mathrm{d} z_{\theta}+\frac{1}{2} \theta \sigma_{\theta}^{2} \mathrm{~d} t
\end{aligned}
$$

where all orders of $\mathrm{d} t$ larger than one are ignored and $\mathrm{d} z^{2}=\mathrm{d} t .^{2}$ The variable $\theta$ can conveniently be written as an Itô process of the form

$$
\begin{aligned}
\theta_{i T} & =\theta_{i 0}+\int_{0}^{T} \mathrm{~d} \theta_{i t} \\
\mathrm{~d} \theta_{i t} & =m_{\theta} \theta_{i t} \mathrm{~d} t+\sigma_{\theta} \theta_{i t} \mathrm{~d} z_{\theta, i t} .
\end{aligned}
$$

Four remarks about this stochastic process are in place. First, a Brownian motion with a drift is the limit of a random walk with uneven probabilities for negative and positive changes. ${ }^{3}$ A positive drift implies that positive changes are more likely to occur than negative changes. The drift rate thus represents the bias of uncertainty. Second, notice that when a geometric

\footnotetext{
${ }^{2} \mathrm{As} \mathrm{d} t \rightarrow 0, \mathrm{~d} t>\mathrm{d} t^{3 / 2} \approx 0$.

${ }^{3}$ See for example Dixit (1993).
} 
Brownian motion has a positive initial value, it will never become negative as $\theta=0$ is an absorbing barrier. Third, the integral in 2 is an Itô integral, which implies that ${ }^{4}$

$$
\left\langle\theta_{i T}\right\rangle_{t}=\theta_{i t} \exp \left[m_{\theta}(T-t)\right] .
$$

Here, the hooks are expected value operators. If one would require that, a priori, uncertainty is unbiased, then one could simply set $m_{\theta}=0 .{ }^{5}$ In the model presented here, no restrictions are placed on the a priori bias of uncertainty. A priori unbiased uncertainty is just a special case. The fourth and last remark concerns the variance of $\theta$. As $\theta$ is lognormally distributed $\left(\theta_{t} \sim \operatorname{LN}\left[\left(m_{\theta}-\frac{1}{2} \sigma_{\theta}^{2}\right)(T-t), \sigma_{\theta}^{2}(T-t)\right]\right)$, the variance of $\theta$ is ${ }^{6}$

$$
\mathcal{V}\left(\theta_{i T}\right)_{t}=\theta_{i t}^{2} \exp \left[2 m_{\theta}(T-t)\right]\left(\exp \left[\sigma_{\theta}^{2}(T-t)\right]-1\right) \text {. }
$$

The variance of $\theta$ is expected to grow over time and accelerate with increases in $m_{\theta}$ or $\sigma_{\theta}$. This implies that the differences between firms are expected to widen over time.

In the model each unit of the intermediate product of variety $i$ is produced with $\eta$ units of foregone consumption $K$ (capital). It is assumed that capital can be reallocated among the intermediate firms instantly and without costs. When $x_{i}$ denotes the quantity produced of variety $i$ and $r$ is the interest rate then the costs of producing this quantity are $r \eta x_{i}$. The cost parameter, $\eta$, is not a constant but a variable that changes randomly over time and that is different for each variety $i$. More specific, it is assumed that $\eta_{i}$ also follows a geometric Brownian motion.

$$
\begin{aligned}
\eta_{i T} & =\eta_{i 0}+\int_{0}^{T} \mathrm{~d} \eta_{i t} \\
\mathrm{~d} \eta_{i t} & =m_{\eta} \eta_{i t} \mathrm{~d} t+\sigma_{\eta} \eta_{i t} \mathrm{~d} z_{\eta, i t} \\
\mathrm{~d} z_{\eta, i t} & =\epsilon_{\eta, i t} \sqrt{\mathrm{d} t} .
\end{aligned}
$$

The expected value and variance of $\eta_{i T}$ are

$$
\begin{aligned}
\left\langle\eta_{i T}\right\rangle_{t} & =\eta_{i t} \exp \left[m_{\eta}(T-t)\right] \\
\mathcal{V}\left(\eta_{i T}\right)_{t} & =\eta_{i t}^{2} \exp \left[2 m_{\eta}(T-t)\right]\left(\exp \left[\sigma_{\eta}^{2}(T-t)\right]-1\right) .
\end{aligned}
$$

The differences between the cost characteristics of firms are expected to change over time. Equations 3 and 7 are examples of Itô stochastic differential equations (SDEs). To allow $\mathrm{d} \theta_{i t}$

\footnotetext{
${ }^{4}$ If $\lim _{n \rightarrow \infty} \sum_{\nu=0}^{n} \theta\left(\tau_{\nu}\right)\left(z\left(t_{\nu+1}\right)-z\left(t_{\nu}\right)\right)=\int \mathrm{d} \theta_{i t} \mathrm{~d} i$ and $\tau_{\nu}=a t_{\nu+1}+(1-a) t_{\nu}$ then Itô integrals have $a=0$. As a result $\theta\left(\tau_{\nu}\right)$ is independent of $z\left(t_{\nu+1}\right)$.

${ }^{5}$ Note that defining the drift rate of $\mathrm{d} \ln \theta$ as $m_{\theta}-\frac{1}{2} \sigma_{\theta}^{2}$ neutralizes the part of the drift rate that is endogenous to the geometric Brownian motion.

${ }^{6}$ The variance of the increments in the logarithm of $\theta$ is given by

$$
\mathcal{V}(\mathrm{d} \ln \theta)=\left\langle(\mathrm{d} \ln \theta)^{2}\right\rangle-\langle\mathrm{d} \ln \theta\rangle^{2}=\sigma_{\theta}^{2} \mathrm{~d} t .
$$

Over period $[t, T]$ this implies $\mathcal{V}(\Delta \ln \theta)=\sigma_{\theta}^{2} \Delta t=\sigma_{\theta}^{2}(T-t)$. For properties of the lognormal distribution see e.g. Aitchison and Brown (1957).
} 
and $\mathrm{d} \eta_{i t}$ to be stochastically related it is assumed that the joint distribution of $\epsilon_{\theta}$ and $\epsilon_{\eta}$ is given by

$$
\begin{aligned}
\left(\epsilon_{\theta, i t}, \epsilon_{\eta, i t}\right) \sim & \mathrm{N}_{2}[0,0,1,1, \mu] \\
\text { with } & |\mu|<1
\end{aligned}
$$

The parameter $\mu$ denotes the correlation between $\epsilon_{\theta, i t}$ and $\epsilon_{\eta, i t}$. Furthermore, the covariances across time and firms are assumed to be zero. A negative $\mu$ means that a decrease in costs is likely to coincide with an increase in quality. A positive $\mu$ implies that lower costs are likely to occur at the same time as lower quality.

The research sector produces designs by means of human capital $\left(H_{A}\right)$ and available knowledge (or stock of designs, $A$ ). Human capital is thus employed in both the final and research sector. Total human capital is $H=H_{Y}+H_{A}$. Suppose that the probability that one person makes a discovery between $t$ and $t+\mathrm{d} t$ is $\lambda$ and each discovery will lead to $\delta A$ new designs. As the knowledge base increases, discoveries become more fruitful. Thus, the number of discovered designs is a Poisson process with flow probability $\lambda$ and jumps of the size $\delta A$. The number of new designs researcher $h \in H_{A}$ is expected to generate is

$$
\left\langle\mathrm{d} A_{h}\right\rangle=\delta A \lambda \mathrm{d} t .
$$

The variance of the number of newly produced designs is

$$
\mathcal{V}\left(\mathrm{d} A_{h}\right)=\delta A \lambda \mathrm{d} t
$$

The total amount of designs discovered by the research sector between $t$ and $t+\mathrm{d} t$ is

$$
\begin{aligned}
\dot{A} & =\int_{0}^{H_{A}} \lambda \delta A \mathrm{~d} h \\
& =\lambda \delta A H_{A},
\end{aligned}
$$

where the dot represents the derivative with respect to time. An increase in $\lambda$ implies an increase in the variance of $\mathrm{d} A_{h}$ and thus more uncertainty for the individual researcher. The uncertainty experienced by researchers is extremely biased: the probability of undiscovering a design is zero, while the probability of discovering a design is positive. For researchers more uncertainty directly implies higher productivity.

\subsection{Downstream impact of uncertainty}

The producer of intermediate goods of variety $i$ is able to set a mark-up over its marginal costs because of the limited substitutability of intermediates implied by the additive production function of the consumption goods sector. The price of intermediate $i$ is

$$
\bar{p}_{i}=\frac{r \eta_{i}}{\alpha} .
$$

The implied inverse demand function for $x_{i}$ is

$$
p_{i}=\alpha H_{Y}^{1-\alpha-\beta} L^{\beta} \theta_{i}^{\alpha} x_{i}^{\alpha-1} .
$$


By equating demand and supply, the produced amount of intermediate $i$ can be constructed:

$$
\bar{x}_{i}=\left(\alpha^{-2} r \eta_{i} H_{Y}^{\alpha+\beta-1} L^{-\beta} \theta_{i}^{-\alpha}\right)^{\frac{1}{\alpha-1}} .
$$

Profits for $\bar{p}$ and $\bar{x}$ are given $\mathrm{by}^{7}$

$$
\pi_{i}=(1-\alpha) \alpha^{\frac{1+\alpha}{\alpha-1}} r^{\frac{\alpha}{\alpha-1}} H_{Y}^{\frac{\alpha+\beta-1}{\alpha-1}} L^{\frac{-\beta}{\alpha-1}} \theta_{i}^{\frac{-\alpha}{\alpha-1}} \eta_{i}^{\frac{\alpha}{\alpha-1}} .
$$

Inserting $\bar{x}_{i}$ from 13 into the production function gives

$$
Y=H_{Y}^{\frac{\alpha+\beta-1}{\alpha-1}} L^{\frac{-\beta}{\alpha-1}} r^{\frac{\alpha}{\alpha-1}} \alpha^{\frac{-2 \alpha}{\alpha-1}} \int_{0}^{A} \theta_{i}^{\frac{-\alpha}{\alpha-1}} \eta_{i}^{\frac{\alpha}{\alpha-1}} \mathrm{~d} i
$$

Although the $\eta_{i}$ and $\theta_{i}$ are stochastic, it can be shown that $\int_{0}^{A} \theta_{i}^{\frac{-\alpha}{\alpha-1}} \eta_{i}^{\frac{\alpha}{\alpha-1}} \mathrm{~d} i$ can be expressed as a simple deterministic function.

\section{Proposition 1 Suppose that the following conditions hold}

(1) intermediate firms started at $t=0$ have identical quality and cost characteristics $(\forall i \in$ $A_{0}: \theta_{i 0}=\theta_{0}$ and $\left.\eta_{i 0}=\eta_{0}\right)$

(2) intermediate firms started at $t>0$ are as profitable as existing firms are on average $\left(\forall i \in\left[A_{t}, A_{t+\mathrm{d} t}\right): \pi_{i t}=\bar{\pi}_{t}\right)$

(3) the number of intermediate firms $\left(A_{t}\right)$ changes deterministically over time

then $\int_{0}^{A} \theta_{i}^{\frac{-\alpha}{\alpha-1}} \eta_{i}^{\frac{\alpha}{\alpha-1}} \mathrm{~d} i$ can be expressed as the deterministic expression

$$
A_{t} \theta_{0}^{k} \eta_{0}^{-k} \exp [\kappa t]
$$

with

$$
\kappa \equiv k m_{\theta}+\frac{1}{2} k(k-1) \sigma_{\theta}^{2}-k m_{\eta}+\frac{1}{2} k(k+1) \sigma_{\eta}^{2}-k^{2} 2 \sigma_{\theta} \sigma_{\eta} \mu
$$

and $k \equiv \frac{-\alpha}{\alpha-1}>0$.

Proof. See subsection A.1.

Using 16 in 15 and taking growth rates yields

$$
\hat{Y}=\frac{\alpha+\beta-1}{\alpha-1} \hat{H}_{Y}+\frac{-\beta}{\alpha-1} \hat{L}+\frac{\alpha}{\alpha-1} \hat{r}+\kappa+\hat{A}
$$

The effect of uncertainty on the growth rate of final output is ambiguous. The second term of 17 shows that if $\alpha<\frac{1}{2}$, an increase in the uncertainty parameter for quality $\left(\sigma_{\theta}\right)$ will reduce $\kappa$ even if $\mu=0$. The effect of more uncertainty in costs $\left(\sigma_{\eta}\right)$ is positive, at least for $\mu \leq 0$.

\footnotetext{
${ }^{7}$ The flow of profits for intermediate firm $i$ is $\pi_{i}=(1-\alpha) \bar{p}_{i} \bar{x}_{i}$ with the price as a mark-up over marginal costs, $\bar{p}_{i}=r \eta_{i} / \alpha$, and the quantity implied by the price and the demand function (13).
} 


\subsection{Upstream impact of uncertainty}

Before an entrepreneur can start producing a certain type of intermediate good, the entrepreneur has to buy a design from the research sector. The price of a particular design is set by the research sector and is assumed not to change after it has been set. Furthermore, it is assumed that each design can only be bought by one specific entrepreneur. Unlike in the Romer model, there is no competition for designs. The entrepreneur thus can only decide when to buy the design, that is, if the entrepreneur buys it at all. These rather restrictive assumptions are necessary to introduce a real-option effect without adding much complexity. ${ }^{8}$

Before an entrepreneur decides to buy a design, she would like to know how much it is likely to be worth. The value of a new design depends on the flow of profits an intermediate firm is expected to generate. If an intermediate firm is faced with uncertainty in quality and costs, what are the implications for the value of the firm? It will be shown in section 5 that $r$ and $H_{Y}$ are constant if the market for human capital clears instantly. Therefore, equation 14 can be simplified to

$$
\pi_{i}=\Gamma \theta_{i}^{k} \eta_{i}^{-k}
$$

where $\Gamma$ is a constant. This expression for profits can be used to describe the behavior of the expected value of a project, $\langle V\rangle$.

Proposition 2 If $\pi$ is represented by 19, the conditions of proposition 1 hold, and the rate of interest, $r$, is constant over time, then $\langle V\rangle$ is a stochastic process with initial value

$$
\left\langle V_{A}(t)\right\rangle=\frac{1}{r-\kappa} \Gamma \theta_{0}^{k} \eta_{0}^{-k} \exp [\kappa t]
$$

and $S D E \mathrm{~d}\langle V\rangle=\langle V\rangle\left(\kappa \mathrm{d} t+k \sigma_{\theta} \mathrm{d} z_{\theta}-k \sigma_{\eta} \mathrm{d} z_{\eta}\right)$.

Proof. See subsection A.2.

The effect of uncertainty on the growth rate of profits is ambiguous. In fact, it is identical to the downstream effect of uncertainty on the growth rate of final output. Again, the second term of 17 shows that if $\alpha<\frac{1}{2}$, an increase in the uncertainty parameter for quality $\left(\sigma_{\theta}\right)$ will reduce $\kappa$ even if $\mu=0$. The effect of more uncertainty in costs is positive, at least for $\mu \leq 0$.

From the proof of proposition 2 follows that if $\eta$ and $\theta$ follow a geometrical Brownian motion, so does $\langle V\rangle$. Following the literature on 'real options', entrepreneurs may postpone irreversible investment when the revenues from the investment are uncertain. ${ }^{9}$ In this model there is an occurrence of irreversible investment: intermediate producers have to pay a lump sum in order to get a design. Given the price of the design set by the research sector, the entrepreneur has to decide whether she will buy the design now or later. Postponing the investment can be a wise thing to do for two reasons. First, the expected value of a project may rise (deterministically) over time. Second, valuable information about the levels of $\eta_{i}$ and $\theta_{i}$ becomes available over time, thus increasing the returns to waiting.

\footnotetext{
${ }^{8}$ Real-option effects can also occur in more competitive settings. See Dixit and Pindyck, 1994, chapters 8 and 9 for examples.

${ }^{9}$ For an overview of real-option theory see Dixit and Pindyck (1994).
} 
From now on it is assumed that uncertainty in quality and costs is external to the firm. Both $\theta_{i}$ and $\eta_{i}$ are observable stochastic variables precisely from the moment that design $i$ has been invented. Without this assumption entrepreneurs would be indifferent about the timing of the purchase of designs.

The conditions under which investing is optimal are given by the application of real-option theory. In short, the procedure is to derive the value of the opportunity to invest. Investment is optimal when the opportunity to invest is as valuable as investing now. In this situation the entrepreneur is indifferent between waiting and investing. As the opportunity to invest cannot be less valuable than investing now, investment is optimal at the point of indifference between waiting and investing.

The value of the opportunity to invest $(F)$ is given by

$$
F(V)=\max _{T}\left[\left(V_{T}-P_{A}\right) e^{-r T}\right] .
$$

Where $P_{A}$ is the irreversible investment which is the price of a design, and $T$ is the unknown time at which the investment is made. The value of the opportunity to invest is equal to the discounted value of the investment project started at the optimal time. At this point in time $\left(T^{*}\right)$ the opportunity to invest is equal to the value of investing immediately

$$
F(V)=V_{T^{*}}-P_{A},
$$

so there is no gain from postponing the investment (the option to postpone is worthless). The value of $V$ at $T^{*}$ will be denoted as $V^{*}$. In order to find the value of $V^{*}$, the value of the option to invest, represented by $F(V)$, has to be determined. The first step here is to write an expression for the behavior of $F$ over time:

$$
r F \mathrm{~d} t=\langle\mathrm{d} F\rangle .
$$

This equation is called a Bellman equation. This equation can be shown to result from 21 . Intuitively 23 can be interpreted as follows: Would the option to invest have been tradable and its risk diversifiable, then the value of the option would have to increase over time $(\langle\mathrm{d} F\rangle / \mathrm{d} t)$ in such a way that it makes up for the foregone revenues from interest $(r F)$. We can obtain $\langle\mathrm{d} F\rangle$ by using Itô's lemma, substituting for $\mathrm{d} V$ from equation 21 and taking the expected value

$$
\langle\mathrm{d} F\rangle=F_{V} \kappa V \mathrm{~d} t+\frac{1}{2} F_{V V} V^{2} k^{2}\left(\sigma_{\theta}^{2}+\sigma_{\eta}^{2}-2 \sigma_{\theta} \sigma_{\eta} \mu\right) \mathrm{d} t .
$$

Insert this into the Bellman equation (23) and divide through $\mathrm{d} t$ to obtain the differential equation

$$
\frac{1}{2} F_{V V} V^{2} k^{2}\left(\sigma_{\theta}^{2}+\sigma_{\eta}^{2}-2 \sigma_{\theta} \sigma_{\eta} \mu\right)+F_{V} \kappa V-r F(V)=0 .
$$

When $V_{t}=0$ it will keep this value forever because $V_{t}$ follows a geometric Brownian motion. Thus, as the opportunity to invest in something that will never be valuable is worthless, the differential equation must satisfy

$$
F(0)=0 \text {. }
$$


Also, from equation 22 follows

$$
F\left(V^{*}\right)=V^{*}-P_{A} .
$$

A third, and last, requirement, called the 'smooth-pasting' condition, is

$$
F_{V}\left(V^{*}\right)=1
$$

Smooth pasting is necessary because when $F=V-P_{A}$ but $\langle\mathrm{d} F\rangle / \mathrm{d} t \neq \mathrm{d} V / \mathrm{d} t$, then the entrepreneur would not be indifferent between investing and postponing.

$F(V)$ can be found by solving the second order linear differential equation 25 using equations 26, 27, and 28. As $F(0)=0$ we know that $F$ should have the following form:

$$
F(V)=B_{1} V^{b_{1}}+B_{2} V^{b_{2}} .
$$

Using this in equation 25 gives

$$
B V^{b}\left[\frac{1}{2} k^{2}\left(\sigma_{\theta}^{2}+\sigma_{\eta}^{2}-2 \sigma_{\theta} \sigma_{\eta} \mu\right) b^{2}+\kappa b-r\right]=0
$$

The fundamental quadratic equation to be solved is

$$
\begin{aligned}
\mathcal{Q}(b) & =\frac{1}{2} k^{2}\left(\sigma_{\theta}^{2}+\sigma_{\eta}^{2}-2 \sigma_{\theta} \sigma_{\eta} \mu\right) b^{2}+\kappa b-r=0 \\
b & =\frac{-\kappa \pm \sqrt{\kappa^{2}+2 k^{2}\left(\sigma_{\theta}^{2}+\sigma_{\eta}^{2}-2 \sigma_{\theta} \sigma_{\eta} \mu\right) r}}{k^{2}\left(\sigma_{\theta}^{2}+\sigma_{\eta}^{2}-2 \sigma_{\theta} \sigma_{\eta} \mu\right)}
\end{aligned}
$$

Here, $b$ must be larger than zero because the value of the option cannot decrease with an increase in the underlying value. The only possible solution is $F(V)=B_{1} V^{b_{1}}$ with

$$
b_{1}=\frac{-\kappa+\sqrt{\kappa^{2}+2 k^{2}\left(\sigma_{\theta}^{2}+\sigma_{\eta}^{2}-2 \sigma_{\theta} \sigma_{\eta} \mu\right) r}}{k^{2}\left(\sigma_{\theta}^{2}+\sigma_{\eta}^{2}-2 \sigma_{\theta} \sigma_{\eta} \mu\right)} .
$$

The equations 27 and 28 give a formulation for $V^{*}$ and $B_{1}$ :

$$
\begin{aligned}
V^{*} & =\frac{b_{1}}{b_{1}-1} P_{A} \\
B_{1} & =\frac{V^{*}-P_{A}}{\left(V^{*}\right)^{b_{1}}}=\frac{\left(b_{1}-1\right)^{b_{1}-1}}{b^{b_{1}} P_{A}^{b_{1}-1}}
\end{aligned}
$$

From 30 it is clear that $b_{1}>1$ has to be satisfied otherwise the intermediate firm would invest while the value of the investment is negative and its price is positive. This implies that $\mu<\left(\sigma_{\theta}^{2}+\sigma_{\eta}^{2}\right) /\left(2 \sigma_{\theta} \sigma_{\eta}\right)$, which is always satisfied as $\mu<1$.

What, however, will be the price of a new design? The research sector will set a price to maximize expected revenues. Suppose that the research sector does not engage in a dynamic pricing strategy and sets only one intertemporal price for each new design. The higher the price is set, the longer it is expected to take before the intermediate producer buys the design. 
Proposition 3 If the research sector can set the price of a design only once, then the research sector will always sell designs immediately after their discovery.

Proof. See subsection A.3.

The price at which newly discovered design are sold is

$$
P_{A(t)}^{*}=\frac{b_{1}-1}{b_{1}} V_{A t} .
$$

Note that no uncertainty about $P_{A}^{*}$ or the time of transaction is left when the research sector decides to set the price in order to sell immediately. In fact, the price of new designs changes deterministically over time. That the time of transaction is not stochastic follows from the assumption that designs are sold at a fixed price. That $P_{A}^{*}$ is not stochastic follows from the assumption that the initial profitability of a new design is equal to the average profitability at that time (condition 2 of proposition 1). All uncertainty is thus transmitted to the intermediate producer.

The assumption that the research sector sets a fixed price for a new design is less restrictive than it may appear to be. In fact, $P_{A}^{*}$ has an alternative interpretation. Notice that $P_{A}^{*}$ is the highest price for which both the research sector and the intermediate producer are not willing to postpone the transaction. $P_{A}^{*}$ could be the outcome of a dynamic 'waiting' game. Suppose the research sector sets $P_{A}=V_{t}$. Now, the intermediate producer can exploit the incentive of the research sector to sell immediately by threatening to postpone the acquisition of the new design. The intermediate producer can only do this in a credible way until the price has dropped to $P_{A}^{*}$ because at $P_{A}^{*}$ it is not optimal anymore for the intermediate producer to postpone.

How will less uncertainty, that is a decrease in $\sigma_{\theta}$ and $\sigma_{\eta}$, affect the price for a business plan, $P_{A}$ ? Suppose that $\sigma_{\theta}, \sigma_{\eta} \rightarrow 0$, then from equation 29 it follows that $b_{1} \rightarrow \infty$, and together with

$$
\lim _{b_{1} \rightarrow \infty} \frac{b_{1}-1}{b_{1}}=1
$$

it implies that

$$
\lim _{\sigma_{\theta}, \sigma_{\eta} \rightarrow 0} P_{A(t)}=\lim _{b_{1} \rightarrow \infty} \frac{b_{1}-1}{b_{1}} V_{A, t}=V_{A, t} .
$$

The research sector receives a low price for designs when there is a lot of uncertainty in the value of the designs.

The expected income of the entrepreneur becomes positive as profits become uncertain as the 'negotiating power' of the entrepreneur increases. Although being rewarded for taking risks seems to be a realistic feature of the model, it brings along two problems. First, there is the problem of the scarcity of entrepreneurial capability. When selling a design, the research sector is confronted with a scarcity of entrepreneurs. There is only one entrepreneur that is willing to buy the design. On the other hand, it is always possible to find a capable entrepreneur. The capability of prospective entrepreneurs is not affected by the number of designs that have been sold previously. This points at the presence of an abundance of entrepreneurs. The paradox can be resolved by assuming that good entrepreneurs are abundant but also extremely heterogenous. These assumptions, however, are not very realistic. 
The second problem concerns the distribution of entrepreneurial income. How does uncertainty about the income of an individual relate to aggregate consumer behavior? One solution here is to assume that entrepreneurs trade shares in their firms with each other. By doing so they can obtain a riskless portfolio of shares. In this case the entrepreneur is rewarded not for taking risks but rather for possessing and using unique talents.

\section{Long-term growth}

Both the downstream and upstream effects of uncertainty in the intermediate sector were shown to be deterministic (see equations 18 and 31). Thus, the long-term growth rate can be determined in approximately the same way as in the model by Romer (1990). First, determine the equilibrium share of human capital employed by the research sector. Second, the resulting share gives the growth rate of the number of intermediate firms. Third, the growth in the final production and other variables are determined.

To get the share of human capital in the final goods sector, the 'wage rate' of human capital has to be found. This can be done by setting the wage rate of the final goods sector equal to the wage rate in the research sector $\left(w_{H_{Y}}=w_{H_{A}}\right)$. In both sectors, the wage rate equals the marginal productivity of human capital. For the research sector, the marginal productivity of human capital is (using equations 31, 20, and 14)

$$
\begin{aligned}
w_{H_{A}, t} & =\frac{\mathrm{d}}{\mathrm{d} H_{A}} P_{A} \dot{A}=\frac{\mathrm{d}}{\mathrm{d} H_{A}} P_{A} \lambda \delta A H_{A} \\
& =\alpha^{\frac{-1-\alpha}{\alpha-1}} r^{\frac{\alpha}{\alpha-1}} H_{Y}^{\frac{\alpha+\beta-1}{\alpha-1}} L^{\frac{-\beta}{\alpha-1}} \frac{b_{1}-1}{b_{1}} \frac{1}{r-\kappa} \theta_{0}^{k} \eta_{0}^{-k} \exp [\kappa t] \lambda \delta A
\end{aligned}
$$

Using 16 in 15 we see that the wage rate for human capital in the final goods sector is

$$
w_{H_{Y}, t}=\frac{1-\alpha-\beta}{1-\alpha} H_{Y}^{\frac{\alpha+\beta-1}{\alpha-1}-1} L^{\frac{-\beta}{\alpha-1}} r^{\frac{\alpha}{\alpha-1}} \alpha^{\frac{-2 \alpha}{\alpha-1}} A \theta_{0}^{k} \eta_{0}^{-k} \exp [\kappa t]
$$

The amount of human capital employed in the final goods sector can be found by equating equations 33 and 34 and solving for $H_{Y}$

$$
\begin{aligned}
& w_{H_{A}}=w_{H_{Y}} \\
& H_{Y}=\frac{b_{1}}{\left(b_{1}-1\right)} \frac{(1-\alpha-\beta)(r-\kappa)}{(1-\alpha) \lambda \delta \alpha} .
\end{aligned}
$$

From 35 follows that $H_{Y}$ can only be constant if $\hat{r}=0$ (at least for $H_{Y}<H$ ). That the interest rate is indeed constant when the market for human capital is in equilibrium can be shown by equating the growth rates of the productivity of human capital in both sectors:

$$
\begin{aligned}
\hat{w}_{H_{A}} & =\hat{w}_{H_{Y}} \\
\kappa+\hat{A}-\frac{\alpha}{\alpha-1} \hat{r}-\frac{\dot{r}}{r-\kappa} & =\kappa+\hat{A}-\frac{\alpha}{\alpha-1} \hat{r} \\
\dot{r} & =0 .
\end{aligned}
$$


Thus, the allocation of human capital between the final goods and research sector is constant (remember that there is no uncertainty in the aggregate). Consequently, the growth rate of $A$ is constant.

$$
\begin{aligned}
\hat{A} & =\lambda \delta H_{A}=\lambda \delta\left[H-\frac{b_{1}}{\left(b_{1}-1\right)} \frac{(1-\alpha-\beta)(r-\kappa)}{(1-\alpha) \lambda \delta \alpha}\right] \\
& =\lambda \delta H+\Lambda(\kappa-r)
\end{aligned}
$$

with

$$
\Lambda \equiv \frac{b_{1}}{\left(b_{1}-1\right)} \frac{(1-\alpha-b)}{(1-\alpha) \alpha} .
$$

Combining equation 18 with $\hat{L}=\hat{H}_{Y}=\hat{r}=0$ gives the growth rate of income:

$$
\hat{Y}=\kappa+\hat{A} .
$$

The amount of capital that is used in the economy consists of two components. First, capital is used for the production of intermediate goods. Second, capital is needed to be able to pay directly for the services of the research sector. The research sector has to be paid instantly by the intermediate firm but this firm cannot recover these costs instantly. Therefore, the intermediate firm has to get a loan to finance the gap in cash-flows. The total amount of capital is the sum of the capital used in intermediate production and the capital needed to finance the cash-flow gap of the intermediate sector $(D)$

$$
K_{t}=\int_{0}^{A} \eta_{i t} \bar{x}_{i t} \mathrm{~d} i+D_{t},
$$

where $x_{i t}$ is given by equation 13 and thus $\eta_{i t} \bar{x}_{i t}=\Xi \theta_{i t}^{k} \eta_{i t}^{-k}$, with $\Xi \equiv(1-\alpha-\beta)^{\frac{-2}{\alpha-1}} r^{\frac{1}{\alpha-1}} H_{Y}^{\frac{\alpha+\beta-1}{\alpha-1}} L^{\frac{-\beta}{\alpha-1}}$. The growth rate of $\int_{0}^{A} \Xi \theta_{i}^{k} \eta_{i}^{-k} \mathrm{~d} i$ is $\hat{A}+\kappa$ (proposition 1 ).

Proposition 4 If the ratio of debt repayment to profits is $\frac{b_{1}-1}{b_{1}}$, then $\hat{K}=\hat{A}+\kappa$.

Proof. See subsection A.4.

As $\frac{C}{Y}=1-\frac{\dot{K}}{Y}=1-\hat{K} \frac{K}{Y}$, which implies $\hat{C}-\hat{Y}=\hat{\hat{K}}+\hat{K}-\hat{Y}$, and $\hat{K}=\hat{Y}$, we have

$$
\hat{C}=\hat{K} .
$$

The long-term growth rate of the economy, $\gamma$, is

$$
\gamma=\hat{A}+\kappa=\lambda \delta H+\Lambda(\kappa-r)+\kappa .
$$

Intertemporal optimization of the utility function implies that $\hat{C}=(r-\rho) / s .{ }^{10}$ Solving for the interest rate yields

$$
r=\frac{s(\lambda \delta H+(\Lambda+1) \kappa)+\rho}{s \Lambda+1}
$$

\footnotetext{
${ }^{10}$ The utility function is given by $\int_{0}^{\infty} U(C) \exp [-\rho t] \mathrm{d} t$ where $U(C)=\frac{C^{1-s}-1}{1-s}$ and $s \geq 0$ and is optimized subject to $\dot{K}=Y-C$ and $\lim _{t \rightarrow \infty} K_{t} \exp [-r t] \geq 0$.
} 
Note that because total capital requirements are deterministic, the interest rate is the risk-free. After substitution of 42 in 41 we find

$$
\gamma=\frac{\lambda \delta H+(\Lambda+1) \kappa-\rho \Lambda}{s \Lambda+1} .
$$

Equations 17, 32, and 38 show that for $\sigma_{\theta}, \sigma_{\eta} \rightarrow 0, \lambda=1$, and $m_{\eta}=m_{\theta}=0$ we get the results identical to that of Romer (1990).

\section{Interpretation of the model}

How does uncertainty affect growth? After inserting 38 into 43,

$$
\gamma=\frac{\lambda \delta H+(\kappa-\rho) \frac{b_{1}}{\left(b_{1}-1\right)} \frac{(1-\alpha-\beta)}{(1-\alpha) \alpha}+\kappa}{s \frac{b_{1}}{\left(b_{1}-1\right)} \frac{(1-\alpha-\beta)}{(1-\alpha) \alpha}+1}
$$

it becomes clear that the equation for growth contains three parameters that are related to uncertainty: $\lambda, \kappa$, and $b_{1}$. As has been explained in section 4, a higher $\lambda$ means both more uncertainty and higher productivity in the research sector. Not surprisingly, $\lambda$ is directly and positively related to the growth rate. The $\kappa$ stands for the aggregate of Jensen's Inequality effects (see next subsection and appendix C). The $b_{1}$ originates from the investment-timing effect (subsection 4.2).

\subsection{The intermediate sector}

The demand for a high-quality low-cost intermediate will be larger than the demand for an inferior and more expensive intermediate. Suppose the 'efficiency-measure' of raw capital devoted to intermediate $i$ is defined as $\theta_{i} / \eta_{i}$ then a rise in the efficiency-measure of the intermediate leads to a rise in demand for the intermediate for two reasons. First, for given input expenditure shares, more final goods can be produced with the same amount of resources (a direct productivity effect). Second, the demand of the final goods sector shifts from the other intermediates towards the more efficient intermediate (a substitution effect). The demand of the intermediate sector for capital will shift accordingly.

Whether an increase in the efficiency-measure of an intermediate causes final production to rise or to fall depends on how much the productivity of an intermediate decreases when more of it is used. If returns to intermediate inputs are sharply decreasing, then both the direct productivity and the substitution effect will be small. The direct productivity effect will be small because for given expenditure shares, a rise in the efficiency measure results in only a small rise in final output. The substitution effect will be small because the gap between the productivity of the 'lucky' ('unlucky') intermediate firm and that of other intermediate firms diminishes fast when output increases (decreases). Equivalently, strong diminishing returns to intermediates imply a low degree of competition between intermediate firms. However, when returns to intermediates are constant, then substitution effects will be infinitely large, competition will 
be perfect, and only one intermediate will be produced. The returns to intermediate inputs thus determine whether the relation between final output and efficiency measures is concave or convex.

The effects of competition and decreasing returns to intermediates can be separated by decomposition of equation 1 into a Cobb-Douglas function with effective capital $\left(K_{e}\right)$ as a third factor and a CES aggregate of intermediate products that defines $K_{e}{ }^{11}$

$$
\begin{aligned}
Y & =L^{1-\alpha-\beta} H_{Y}^{\beta} K_{e}^{\alpha} \\
K_{e} & \equiv\left(\int_{0}^{A}\left(\theta_{i} x_{i}\right)^{\alpha} \mathrm{d} i\right)^{\frac{1}{\alpha}} .
\end{aligned}
$$

The optimal composition of effective capital can be derived by maximizing $K_{e}$ with respect to the $x_{i}$ and subject to a budget constraint:

$$
\max _{x_{i}} \mathfrak{L}=\left(\int_{0}^{A}\left(\theta_{i} x_{i}\right)^{\alpha} \mathrm{d} i\right)^{\frac{1}{\alpha}}+\lambda\left(K_{0}-r \int_{0}^{A} \eta_{i} x_{i} \mathrm{~d} i\right) .
$$

The elasticities of substitution for changes in $\theta$ and $\eta$ are

$$
\begin{aligned}
\sigma_{x \theta} & \equiv \frac{\mathrm{d}\left(x_{i} / x_{j}\right)}{\mathrm{d}\left(\theta_{i} / \theta_{j}\right)} \frac{\left(\theta_{i} / \theta_{j}\right)}{\left(x_{i} / x_{j}\right)}=\frac{-\alpha}{\alpha-1} \\
\sigma_{x \eta} & \equiv \frac{\mathrm{d}\left(x_{i} / x_{j}\right)}{\mathrm{d}\left(\eta_{i} / \eta_{j}\right)} \frac{\left(\eta_{i} / \eta_{j}\right)}{\left(x_{i} / x_{j}\right)}=\frac{1}{\alpha-1},
\end{aligned}
$$

implying that

\begin{tabular}{c|ccc} 
& $\alpha=0$ & $\alpha=1 / 2$ & $\alpha \uparrow 1$ \\
\hline$\sigma_{x \theta}$ & 0 & 1 & $\infty$ \\
$\sigma_{x \eta}$ & -1 & -2 & $-\infty$
\end{tabular}

More competition between intermediate producers magnifies the impact of a change in quality or costs. Equation 13 confirms this result. Stronger competition in the intermediate sector increases the convexity (or reduces the concavity) of $x_{i}\left(\theta_{i}, \eta_{i}\right)$, thereby making the effects of uncertainty on the expected value of $x_{i}$ more positive (less negative). Note that for $\alpha=1 / 2$ the function $x_{i}\left(\theta_{i}, \eta_{i}\right)$ is linear in $\theta_{i}$, and that as, a consequence, the level of uncertainty does not affect the expected value of $x_{i}$.

In order to consider the contribution of an intermediate product to final output, one also has to consider the decreasing returns to intermediates. Ignoring competition in product markets, this contribution can be defined as

$$
Y_{i} \equiv L^{1-\alpha-\beta} H_{Y}^{\beta}\left(\theta_{i} \frac{K_{i}}{\eta_{i}}\right)^{\alpha}
$$

\footnotetext{
${ }^{11}$ This approach has also been followed by Zon, Meijers, and Yetkiner (1999).
} 
Decreasing returns to intermediates cause $Y_{i}\left(\theta_{i}, \eta_{i}\right)$ to be concave in $\theta_{i}$ and, consequently, the relation between uncertainty and the expected value of $Y_{i}$ will be negative. Decreasing returns to intermediates also reduce the convexity of $Y_{i}\left(\theta_{i}, \eta_{i}\right)$ in $\eta_{i}$.

The combined effects of both competition and decreasing returns to intermediates are made visible by equation 15 . The equilibrium contribution of an intermediate product to final output is

$$
Y_{i}=H_{Y}^{\frac{\alpha+\beta-1}{\alpha-1}} L^{\frac{-\beta}{\alpha-1}} r^{\frac{\alpha}{\alpha-1}}(1-\alpha-\beta)^{\frac{-2 \alpha}{\alpha-1}} \theta_{i}^{\frac{-\alpha}{\alpha-1}} \eta_{i}^{\frac{\alpha}{\alpha-1}}
$$

The corresponding substitution elasticities are

$$
\begin{aligned}
\sigma_{Y \theta} & \equiv \frac{\mathrm{d}\left(Y_{i} / Y_{j}\right)}{\mathrm{d}\left(\theta_{i} / \theta_{j}\right)} \frac{\left(\theta_{i} / \theta_{j}\right)}{\left(Y_{i} / Y_{j}\right)}=\frac{-\alpha}{\alpha-1}=k \\
\sigma_{Y \eta} & \equiv \frac{\mathrm{d}\left(Y_{i} / Y_{j}\right)}{\mathrm{d}\left(\eta_{i} / \eta_{j}\right)} \frac{\left(\eta_{i} / \eta_{j}\right)}{\left(Y_{i} / Y_{j}\right)}=\frac{\alpha}{\alpha-1}=-k,
\end{aligned}
$$

and thus

\begin{tabular}{c|ccc} 
& $\alpha=0$ & $\alpha=1 / 2$ & $\alpha \uparrow 1$ \\
\hline$\sigma_{Y \theta}$ & 0 & 1 & $\infty$ \\
$\sigma_{Y \eta}$ & 0 & -1 & $-\infty$
\end{tabular}

Taking account of both competition and decreasing returns to intermediate input effects, it can be concluded that the total Jensen's Inequality effect is negative for $\theta$ if $\alpha<1 / 2$, positive for $\theta$ if $\alpha>1 / 2$, and positive for $\eta$ for all $\alpha$.

Recalling that

$$
\kappa \equiv k m_{\theta}+\frac{1}{2} k(k-1) \sigma_{\theta}^{2}-k m_{\eta}+\frac{1}{2} k(k+1) \sigma_{\eta}^{2}-k^{2} 2 \sigma_{\theta} \sigma_{\eta} \mu,
$$

we see that $\kappa$ comprises the effects of changes in the mean and variance of $\theta$ and $\eta$ on $Y$. The first order (mean) effects, $k m_{\theta}$ and $-k m_{\eta}$, are due to the drift of $\theta$ and $\eta$. The second order (variance) effects, $\frac{1}{2} k(k-1) \sigma_{\theta}^{2}, \frac{1}{2} k(k+1) \sigma_{\eta}^{2}$, and $-k^{2} 2 \sigma_{\theta} \sigma_{\eta} \mu$ are due to Jensen's Inequality. ${ }^{12}$ Second order effects change the growth rate of $Y$ because of the growth in the variance of the cost and quality characteristics of firms that results from micro-uncertainty.

Competition in the intermediate sector leads to a continuous reallocation of capital goods. This reallocation of capital, which might in practice take the form of sales, mergers, and acquisitions, leads to a more productive use of capital. This, in turn, increases the demand for capital. Besides competition, two conditions are important for the occurrence of reallocation of capital. First, capital has to be flexible. Would reallocation of capital be impossible or very costly, then this would fix the output levels of intermediate firms and prohibit substitution.

\footnotetext{
${ }^{12}$ Algebraically, $\kappa$ is the result of the application of Itô's lemma to equation 15 (see subsection A.1). An intuitive explanation of the relation between Itô's lemma and Jensen's Ineqality starts by considering that applying Itô's lemma is identical to making a linear approximation to the increments of a function of a stochastic variable. This is equivalent to computing the expected increments of that function. Therefore, the second-order effects are due to Jensen's Inequality.
} 
Second, diversity is required for substitution. This is why micro-uncertainty is less harmful than aggregate uncertainty. In case of aggregate uncertainty, there's either an abundance or shortage of resources. With micro-uncertainty and some costless flexibility, resources can be used more productively.

Another consequence of micro-uncertainty concerns the distribution of the size of intermediate firms. The size of intermediate firm $i$ is a function of $\theta_{i}$ and $\eta_{i}$ (equation 13). The size of an intermediate firm follows a geometric Brownian motion with normally distributed increments because $\theta_{i}$ and $\eta_{i}$ do. Therefore, the size of intermediate firms will be lognormally distributed. As the variance of the distribution of $\theta_{i}$ and $\eta_{i}$ keeps on growing over time, so will the variance of the distribution of firm size. The intermediate sector will be characterized by increasing numbers of very small and very big firms. ${ }^{13}$

\subsection{The market for human capital}

Consider the effect of $\sigma_{\theta}$ and $\sigma_{\eta}$ on the market for human capital. How does the growth of the variance of $\theta$ and $\eta$, caused by uncertainty, affect the growth of the number of intermediates? An increase in the variance of $\theta$ or $\eta$ changes the price of new designs for three reasons. First, depending on the intermediate input substitution effect, a larger variance may give rise to higher expected profits, and thus the expected value of a new design will also be higher. Second, a larger variance will cause the gap between the value of the design and its actual price to widen via the real-option effect (this is where $b_{1}$ comes in). Third, a higher variance causes the productivity of aggregate capital to change, and savings and interest rates will adjust accordingly. A higher interest rate will reduce the present value of designs, while a lower interest rate will lead to a higher value.

A change in the price of a design will change the productivity of human capital in the research sector. If the productivity of human capital in the research sector grows at a higher rate than the productivity of human capital in the final goods sector, then human capital will start shifting towards the research sector until the gap between the growth rates of productivity has disappeared.

That the share of human capital in the research sector is constant if the market for human capital is in equilibrium, is ensured by the following mechanism. Acceleration of the production of intermediate designs, induced by an arbitrary shift of human capital, will cause an acceleration in the demand for capital needed to produce the new intermediate goods and to finance the purchase of designs. Acceleration in the demand for capital will cause the rate of interest to grow. A rise in the interest rate causes the price of designs to drop, which leads to the movement of human capital in the opposite direction. From equation 36 it can be seen that the interest rate has to be constant if the market for human capital is to stay in equilibrium. Equation 35 in turn shows that a constant interest rate implies a fixed allocation of human capital.

\footnotetext{
${ }^{13}$ There might be convergence in the distributions of firm characteristics and size if it is assumed that 'unlucky' try to imitate 'lucky' firms.
} 


\subsection{Uncertainty and growth}

The exact derivation of the relations between $\sigma_{\theta}$ and $\gamma$ and between $\sigma_{\eta}$ and $\gamma$, can be found in appendix B. A summary of the impact of uncertainty on economic growth can be found in tables 1 and 2. From the first rows of tables 1 and 2 (Jensen's Inequality), it can be seen that the direct effects of $\sigma_{\theta}$ and $\sigma_{\eta}$ on $\gamma$ have the same sign as their effects on $\hat{Y}$ when keeping $A$ constant (equation 18). This is to be expected: a more (less) efficient final goods sector should lead to faster (slower) growth.

The second rows of tables 1 and 2 indicate that if the 'autonomous' growth rate of final sector output, $\kappa$, is high, uncertainty stimulates growth through an increase in the investment-timing effect. This is a somewhat puzzling result as a larger investment-timing effect implies a decrease in the productivity of the research sector. The key to this paradox lies in the observation that employing more human capital in the research sector does not necessarily result in a higher longterm growth rate of final output. If $\kappa>\frac{\rho+s \lambda \delta H}{1-s}$, human capital employed in the final output sector will be more productive in the long term than human capital employed in the research sector will be. Therefore, a larger gap between the price of a design and its value, induced by more uncertainty, will actually stimulate economic growth by increasing the share of human capital that is employed in the final goods sector. This leads to the interesting conclusion that research can be detrimental to growth.

The third rows of tables 1 and 2 are about the interaction of the J.I.-effect and the investment-timing effect (the effect of $\kappa$ on $b_{1}$ ). As the expected value of a design is growing at rate $\kappa$, a higher $\kappa$ makes postponing the purchase of a design more attractive. As a result, the gap between the price of a design and its value will widen. A higher $\kappa$ will reduce the productivity of the research sector through the investment-timing effect.

To get a clearer view on the effects of uncertainty, we may adjust the values of $m_{\theta}$ and $m_{\eta}$ in such a way that some effects are neutralized. For example, J.I.-effects can be neutralized by setting $\kappa$ to zero through defining $m_{\theta} \equiv-\frac{1}{2}(k-1) \sigma_{\theta}^{2}, m_{\eta} \equiv \frac{1}{2}(k+1) \sigma_{\eta}^{2}$, and $\mu=0$. When $\kappa=0$ by construction, tables 1 and 2 show that an increases in either $\sigma_{\theta}$ or $\sigma_{\eta}$ will lead to a slow-down in economic growth. The reason is that the demand for designs is reduced as entrepreneurs see the value of their option to postpone investment increase.

\section{Micro-uncertainty and economic policy}

Can governments stimulate growth by influencing micro-uncertainty? The relations between uncertainty and growth that have been found in this model, do not imply that governments can stimulate growth by simply adjusting the level of uncertainty. It is important to realize that trying to influence uncertainty will in practise involve a change in the a priori bias of uncertainty. For example, a policy effectively aimed at protecting property rights reduces the risk of property being stolen or destroyed. As theft and destruction (whether it is expected, or not) generally lead to losses in efficiency, enforcing property rights results in higher efficiency and less uncertainty at the same time. In this case, reduction of uncertainty stimulates growth in a trivial way. As a counterexample, governments that try to reduce uncertainty by obstructing innovation should not be surprised to end up with slow economic growth. 
Table 1: Growth $(\gamma)$ and uncertainty in quality $\left(\sigma_{\theta}\right)$

\begin{tabular}{|c|c|c|c|c|}
\hline & \multicolumn{2}{|c|}{$\begin{array}{c}\kappa>\frac{\rho+s \lambda \delta H}{1-s} \\
\alpha<\frac{1}{\alpha} \mid \alpha>\frac{1}{1}\end{array}$} & \multicolumn{2}{|c|}{$\kappa<\frac{\rho+s \lambda \delta H}{1-s}$} \\
\hline $\begin{array}{c}\text { Jensen's Inequality } \\
\qquad\left(\frac{\partial \gamma}{\partial \kappa} \frac{\partial \kappa}{\partial \sigma_{\theta}}\right)\end{array}$ & - & + & - & + \\
\hline $\begin{array}{l}\text { Timing } \\
\qquad\left(\frac{\partial \gamma}{\partial b_{1}} \frac{\partial b_{1}}{\partial \sigma_{\theta}}\right)\end{array}$ & + & + & - & - \\
\hline $\begin{array}{l}\text { Interaction } \\
\qquad\left(\frac{\partial \gamma}{\partial b_{1}} \frac{\partial b_{1}}{\partial \kappa} \frac{\partial \kappa}{\partial \sigma_{\theta}}\right)\end{array}$ & - & + & + & - \\
\hline Total & $+/-$ & + & $+/-$ & $+/-$ \\
\hline
\end{tabular}

Note: $\mu=0$

Table 2: Growth $(\gamma)$ and uncertainty in costs $\left(\sigma_{\eta}\right)$

\begin{tabular}{l|c|c} 
& $\kappa>\frac{\rho+s \lambda \delta H}{1-s}$ & $\kappa<\frac{\rho+s \lambda \delta H}{1-s}$ \\
\hline Jensen's Inequality $\left(\frac{\partial \gamma}{\partial \kappa} \frac{\partial \kappa}{\partial \sigma_{\eta}}\right)$ & + & + \\
Timing $\left(\frac{\partial \gamma}{\partial b_{1}} \frac{\partial b_{1}}{\partial \sigma_{\eta}}\right)$ & + & - \\
Interaction $\left(\frac{\partial \gamma}{\partial b_{1}} \frac{\partial b_{1}}{\partial \kappa} \frac{\partial \kappa}{\partial \sigma_{\eta}}\right)$ & + & - \\
Total & + & $+/-$
\end{tabular}

Note: $\mu=0$ 
If a policy would be effective in altering a priori unbiased uncertainty, then it would still be difficult to evaluate its effectiveness in stimulating economic growth. In a real economy the number of non-linear relations at the micro-level is too large to be sure about the kind of effect such a policy might have. Therefore, policies aimed at reducing uncertainty with a bias toward inefficiency and policies aimed at stimulating uncertainty with a bias toward efficiency are more likely to be successful than policies that have the objective to reduce a priori neutral uncertainty.

Finally, the results presented in this paper suggest that long-term growth can be stimulated by promoting both diversity and competition.

\section{Concluding remarks}

A model has been presented in which micro-level uncertainty influences long-term economic growth. In part, this result stems from the fact that uncertainty can be biased. Furthermore, this bias can be both endogenous and exogenous to the model. Diminishing returns to intermediate inputs and competition in the intermediate sector are the sources of endogenous bias in the model. Micro-uncertainty leads to growth in the variance of the quality and cost characteristics of firms. This growing heterogeneity, in turn, stimulates the production of final goods because less efficient intermediates are partly substituted with more efficient intermediates.

Besides through being biased, uncertainty may also affect economic growth through investmenttiming (real-option) effects. Empirical studies suggest that such effects are important when investment are irreversible as is the case for research expenditure. Economic growth may slow down when research expenditure is postponed in reaction to more uncertainty. Furthermore, the endogenous bias of uncertainty may amplify or reduce timing effects.

The model demonstrates that the implications of uncertainty for economic growth are probably much larger than they appear to be from aggregate empirical studies for two reasons. First, the model shows that firm-level volatility is important even if it cancels out in the aggregate. Empirical studies that use aggregate measures of volatility thus underestimate the importance of uncertainty. Second, the model shows that uncertainty can have several effects on economic growth, possibly working in different directions. By not separating these different effects, it is not unexpected that empirical studies do not find strong relations between volatility and growth and that different studies come up with different results. For example, the positive relation between volatility and growth found in the UK and US and the negative relation found in panel data studies might be explained by the high degree of competition in the UK and US. Also, uncertainty may drive a wedge between growth in final output and growth in the variety of inputs. It has been shown that research can be harmful for long-term economic growth for some cases. 


\section{A Proofs of propositions}

\section{A.1 Proposition 1}

Proof. For notational convenience write

$$
\int_{0}^{A_{t}} \theta_{i}^{k} \eta_{i}^{-k} \mathrm{~d} i=\int_{0}^{A_{t}} g_{i} \mathrm{~d} i
$$

The process of finding a solution for $\int_{0}^{A_{t}} g_{i} \mathrm{~d} i$, consists of three steps. First, an expression for $\mathrm{d} g$ has to be found. Second, the expected value of $g_{i}$ is derived. Third, it is shown that the sum of the $g_{i}$ is a deterministic function.

1. An expression for $\mathrm{d} g$ can be obtained from the application of the generalized Itô's lemma ${ }^{14}$

$$
\mathrm{d} g=\frac{\partial g}{\partial \theta} \mathrm{d} \theta+\frac{1}{2} \frac{\partial^{2} g}{\partial \theta^{2}}(\mathrm{~d} \theta)^{2}+\frac{\partial g}{\partial \eta} \mathrm{d} \eta+\frac{1}{2} \frac{\partial^{2} g}{\partial \eta^{2}}(\mathrm{~d} \eta)^{2}+\frac{\partial g}{\partial \theta \partial \eta} \mathrm{d} \theta \mathrm{d} \eta .
$$

All terms involving higher orders of $\mathrm{d} t$ can safely be ignored (Itô's lemma).

$$
\begin{aligned}
\mathrm{d} g & \left.=g\left[\begin{array}{c}
k m_{\theta}+\frac{1}{2} k(k-1) \sigma_{\theta}^{2} \\
-k m_{\eta}+\frac{1}{2} k(k+1) \sigma_{\eta}^{2} \\
-k^{2} 2 \sigma_{\theta} \sigma_{\eta} \mu \\
+k \sigma_{\theta} \mathrm{d} z_{\theta}-k \sigma_{\eta} \mathrm{d} z_{\eta}
\end{array}\right) \mathrm{d} t\right] \\
& =g\left[\kappa \mathrm{d} t+k \sigma_{\theta} \mathrm{d} z_{\theta}-k \sigma_{\eta} \mathrm{d} z_{\eta}\right]
\end{aligned}
$$

Here, the following multiplication rule is applied $\mathrm{d} z_{\theta, i t} \mathrm{~d} z_{\eta, i t}=\mu \mathrm{d} t$. Equation 45 shows that $g$ follows an Itô process.

2. The value of $g$ at time $t=T$ is

$$
\begin{aligned}
g_{T} & =g_{0}+\int_{0}^{T} \mathrm{~d} g_{t} \\
& =g_{0}+\int_{0}^{T} g_{t} \kappa \mathrm{d} t+\int_{0}^{T} g_{t} k \sigma_{\theta} \mathrm{d} z_{\theta, t}-\int_{0}^{T} g_{t} k \sigma_{\eta} \mathrm{d} z_{\eta, t} .
\end{aligned}
$$

As $g_{t}$ is independent of both $\mathrm{d} z_{\theta, t}$ and $\mathrm{d} z_{\eta, t}$,

$$
\left\langle\int_{0}^{T} g_{t} k \sigma_{\theta} \mathrm{d} z_{\theta, t}\right\rangle=\left\langle\int_{0}^{T} g_{t} k \sigma_{\eta} \mathrm{d} z_{\eta, t}\right\rangle=0
$$

where the hooks denote expected value operators. The solution for the expected value of 46 is

$$
\left\langle g_{T}\right\rangle_{t=0}=g_{0} \exp [\kappa T] .
$$

\footnotetext{
${ }^{14} \mathrm{~A}$ proof of Itô's lemma can be found in Malliaris and Brock (1982).
} 
3. First, consider the firms $i \in\left[0, A_{0}\right)$. These firms are all the firms that started at $t=0$. Because by assumption:

- the number of firms is infinite,

- all firms are identical at $t=0,($ condition 1$)$ and

- $\mathrm{d} z_{a, i t}$ is independent of $\mathrm{d} z_{b, j u}$ for $a, b \in\{\eta, \theta\}$ given that either $i \in A / j$ or $t \neq u$,

the sum of all $g_{i}$ at time $T$ is a deterministic function that equals the sum of the expected values of $g_{i T}{ }^{15}$

$$
\int_{0}^{A_{0}} g_{i T} \mathrm{~d} i=\int_{0}^{A_{0}} g_{0} \exp [\kappa T] \mathrm{d} i .
$$

Second, consider the firms $j \in\left[A_{t}, A_{t+\mathrm{d} t}\right)$. These firms are all the firms that started between $[t, t+\mathrm{d} t)$. The sum of the $g_{j}$ changes over time $(T>t)$ according to

$$
\begin{aligned}
\int_{A_{t}}^{A_{t+\mathrm{d} t}} g_{j T} \mathrm{~d} j & =\int_{A_{t}}^{A_{t+\mathrm{d} t}} g_{A_{t}} \exp [\kappa(T-t)] \mathrm{d} j \\
& =\left(A_{t+\mathrm{d} t}-A_{t}\right) \theta_{t}^{k} \eta_{t}^{-k} \exp [\kappa(T-t)] \\
& =\dot{A}_{t} \theta_{t}^{k} \eta_{t}^{-k} \exp [\kappa(T-t)]
\end{aligned}
$$

Note that all firms started at the same time have identical initial values for $\eta$ and $\theta$ (condition 2).

Third, consider the firms $i \in A_{T}$. The sum of the $g_{i}$ changes over time according to

$$
\int_{0}^{A_{T}} g_{i T} \mathrm{~d} i=\int_{0}^{A_{0}} g_{0} \exp [\kappa T] \mathrm{d} i+\int_{0}^{T} \dot{A}_{t} \theta_{t}^{k} \eta_{t}^{-k} \exp [\kappa(T-t)] \mathrm{d} t .
$$

This shows that $\int_{0}^{A_{T}} g_{i T} \mathrm{~d} i$ is deterministic for deterministic changes in $A$ (condition 3 ). Suppose the starting values of $g$ for new firms are such that

$$
\pi_{A t}=\bar{\pi}_{t}=\frac{1}{A} \int_{0}^{A} \Gamma g_{i} \mathrm{~d} i=\Gamma g_{0} \exp [\kappa t]
$$

(condition 2), and thus

$$
g_{A t}=g_{0} \exp [\kappa t]
$$

\footnotetext{
${ }^{15}$ Suppose that firm $\nu$ (with $\left.0 \leq \nu \leq n\right)$ is appointed a fraction $\left[i_{\nu}, i_{\nu+1}\right]$ of the domain of $i \in[0, A]$ and that the characteristics of firm $\nu$ depend on $\iota_{\nu} \in\left[i_{\nu}, i_{\nu+1}\right]$, then the sum of $g\left(\iota_{\nu}\right)$ over all $n$ firms is $\sum_{\nu=0}^{n} g\left(\iota_{\nu}\right)\left(i_{\nu+1}-i_{\nu}\right)$. The limit of this sum for $n \rightarrow \infty$ is $\int_{0}^{A} g_{i} \mathrm{~d} i$. Also, as $n \rightarrow \infty$ the sum of $g\left(\iota_{\nu}\right)$ converges in probability to the sum of the expected values of the $g\left(\iota_{\nu}\right)$.
}

$$
\operatorname{plim} \sum_{\nu=0}^{n} g\left(\iota_{\nu}\right)\left(i_{\nu+1}-i_{\nu}\right)=\int_{0}^{A}\left\langle g_{i}\right\rangle \mathrm{d} i
$$

The sum of the $g_{i}$ converges to the sum of the expected $g_{i}$ with probability one as $n \rightarrow \infty$. 
then the sum of the $g_{j}$ changes over time according to

$$
\begin{aligned}
\int_{0}^{A_{T}} g_{i T} \mathrm{~d} i & =\int_{0}^{A_{0}} g_{0} \exp [\kappa T] \mathrm{d} i+\int_{0}^{T} \dot{A}_{t} g_{0} \exp [\kappa t] \exp [\kappa(T-t)] \mathrm{d} t \\
& =\int_{0}^{A_{0}} g_{0} \exp [\kappa T] \mathrm{d} i+\int_{0}^{T} \dot{A}_{t} g_{0} \exp [\kappa T] \mathrm{d} t \\
& =A_{t} \theta_{0}^{k} \eta_{0}^{-k} \exp [\kappa T] .
\end{aligned}
$$

\section{A.2 Proposition 2}

Proof. In order to find the SDE for $V$, the SDE for $\pi$ has to be derived first. An expression for $\mathrm{d} \pi$ can be found using Itô's lemma in a similar way as in equation 45

$$
\begin{aligned}
\mathrm{d} \pi & \left.=\pi\left[\begin{array}{c}
k m_{\theta}+\frac{1}{2} k(k-1) \sigma_{\theta} \\
-k m_{\eta}+\frac{1}{2} k(k+1) \sigma_{\eta} \\
-k^{2} 2 \sigma_{\theta} \sigma_{\eta} \mu \\
+k \sigma_{\theta} \mathrm{d} z_{\theta}-k \sigma_{\eta} \mathrm{d} z_{\eta}
\end{array}\right) \mathrm{d} t\right] \\
& =\pi\left(\kappa \mathrm{d} t+k \sigma_{\theta} \mathrm{d} z_{\theta}-k \sigma_{\eta} \mathrm{d} z_{\eta}\right) .
\end{aligned}
$$

The expected profits at $\tau$ periods from $t=0$ are

$$
\langle\pi(\tau)\rangle_{t=0}=\Gamma \theta_{0}^{k} \eta_{0}^{-k} \exp [\kappa \tau]
$$

The value of starting a new firm at time $t$ is

$$
V_{t}=\int_{t}^{\infty} \exp \left(-\int_{t}^{\tau} r(s) \mathrm{d} s\right) \pi(\tau) \mathrm{d} \tau
$$

From equation 36 follows that the interest rate $r$ is constant. Therefore, $V$ becomes

$$
V_{t}=\int_{t}^{\infty} \exp [-r(\tau-t)] \pi(\tau) \mathrm{d} \tau
$$

The expected value of a design is

$$
\left\langle V_{t}\right\rangle=\frac{1}{r-\kappa} \pi_{t} \quad \text { iff } r>\kappa
$$

The construction of the model ensures that $r>\kappa .{ }^{16}$

\footnotetext{
${ }^{16}$ Suppose that $r$ approaches $\kappa$ from above. Then ceteris paribus, the expected value of a design increases. This will increase the productivity of human capital in research, causing a shift of human capital towards research. As a consequence intermediate products become cheaper inputs relative to human capital. The increase in the demand for intermediate products will induce a larger demand for physical capital, which will put increasingly more upward pressure on the interest rate. Furthermore, a decline in the interest rate will stimulate the introduction of new intermediate products. This will also cause the demand for capital to increase. Concluding, in general equilibrium, the interest rate will always be higher than $\kappa$.
} 
Because $\frac{1}{r-\kappa}$ is constant, the expression for $\mathrm{d}\langle V\rangle$ can simply be derived from equation 51:

$$
\begin{aligned}
\mathrm{d}\langle V\rangle & =\frac{1}{r-\kappa} \mathrm{d} \pi \\
& =\langle V\rangle\left(\kappa \mathrm{d} t+k \sigma_{\theta} \mathrm{d} z_{\theta}-k \sigma_{\eta} \mathrm{d} z_{\eta}\right) .
\end{aligned}
$$

Combining 50 with 19 gives the initial profits of immediate implementation of a new design,

$$
\pi_{A}(t)=\Gamma \theta_{0}^{k} \eta_{0}^{-k} \exp [\kappa t] .
$$

Using this with 53 yields the initial expected value of a design produced at time $t$,

$$
\left\langle V_{A}(t)\right\rangle=\frac{1}{r-\kappa} \Gamma \theta_{0}^{k} \eta_{0}^{-k} \exp [\kappa t] .
$$

\section{A.3 Proposition 3}

Proof. The optimization problem is

$$
\begin{aligned}
& \max _{\tau^{*}, P_{A}} \int_{t}^{\infty} \exp \left[-r \tau^{*}\right] P_{A} f\left(\tau^{*}\right) \mathrm{d} \tau \\
& \tau^{*}=\tau \mid\left(P_{A}=\frac{b_{1}-1}{b_{1}}\left\langle V_{\tau}\right\rangle\right),
\end{aligned}
$$

with $\tau^{*} \geq t$ as the moment of transaction and $f\left(\tau^{*}\right)$ as its pdf. The research sector has to set a price that is expected to lead to the optimal waiting time / price combination. Substitution of $P_{A}$ and $V_{\tau}$ (from 30 and 20 respectively) yields

$$
\begin{aligned}
& \max _{\tau^{*}} \int_{t}^{\infty} \exp \left[-r\left(\tau^{*}-t\right)\right] \frac{b_{1}-1}{b_{1}} \frac{1}{r-\kappa} \Gamma \theta_{0}^{k} \eta_{0}^{-k} \exp \left[\kappa \tau^{*}\right] f\left(\tau^{*}\right) \mathrm{d} \tau \\
& \max _{\tau^{*}} \int_{t}^{\infty} \exp \left[(\kappa-r) \tau^{*}+r t\right] \frac{b_{1}-1}{b_{1}} \frac{1}{r-\kappa} \Gamma \theta_{0}^{k} \eta_{0}^{-k} f\left(\tau^{*}\right) \mathrm{d} \tau .
\end{aligned}
$$

As $\kappa-r<0$, the lower the mean of $\tau^{*}$ will be, the higher will be the revenues for the research sector, irrespective of the particular form of the pdf $f\left(\tau^{*}\right)$. Consequently, the research sector will sell as soon as possible, that is at $\tau^{*}=t$.

\section{A.4 Proposition 4}

Proof. The cash-flow gap $(D)$ consists of the payments to the research sector minus the part of the profits to which the research sector is entitled, plus the interest costs over the loan. ${ }^{17}$

$$
\begin{aligned}
D_{t} & =D_{0}+\int_{0}^{t} \dot{A}_{\tau} P_{A, \tau} \mathrm{d} \tau-\int_{0}^{t} A_{\tau} \frac{b_{1}-1}{b_{1}} \pi_{\tau} \mathrm{d} \tau+\int_{0}^{t} r D_{\tau} \mathrm{d} \tau \\
& =D_{0}+\int_{0}^{t}\left(\frac{b_{1}-1}{b_{1}}\left(\frac{\lambda \delta H_{A}}{r-\kappa}-1\right)\right) A_{\tau} \pi_{\tau} \mathrm{d} \tau+\int_{0}^{t} r D_{\tau} \mathrm{d} \tau .
\end{aligned}
$$

\footnotetext{
${ }^{17}$ These interest costs are through the discounting of profits already accounted for in $P_{A}$.
} 
The second line is result of substitution of $P_{A}$ and $\dot{A}$. Differentiating with respect to time and dividing by $D_{t}$ yields the growth in the cash-flow gap over time

$$
\hat{D}_{t}=\frac{\left(\frac{b_{1}-1}{b_{1}}\left(\frac{\lambda \delta H_{A}}{r-\kappa}-1\right)\right) A_{t} \pi_{t}}{D_{t}}+r .
$$

Is the long-term growth rate of $D$ stable? To answer this question, consider the relative acceleration of the cash-flow gap:

$$
\widehat{\hat{D}}_{t}=\hat{A}+\kappa-\hat{D}_{t} \text {. }
$$

Clearly the relative acceleration of $D$ converges to zero, implying that $\hat{D}_{t}=\hat{A}+\kappa$. Thus, both terms of equation 40 grow at the same deterministic rate.

\section{B Derivation of $\frac{\mathrm{d} \gamma}{\mathrm{d} \sigma_{\theta}}$ and $\frac{\mathrm{d} \gamma}{\mathrm{d} \sigma_{\eta}}$}

The effects of uncertainty on growth run through $\kappa$ and $b_{1}$ in the following manner:

$$
\begin{aligned}
\frac{\mathrm{d} \gamma}{\mathrm{d} \sigma_{\theta}} & =\frac{\partial \gamma}{\partial \kappa} \frac{\partial \kappa}{\partial \sigma_{\theta}}+\frac{\partial \gamma}{\partial b_{1}} \frac{\partial b_{1}}{\partial \sigma_{\theta}}+\frac{\partial \gamma}{\partial b_{1}} \frac{\partial b_{1}}{\partial \kappa} \frac{\partial \kappa}{\partial \sigma_{\theta}} \\
\frac{\mathrm{d} \gamma}{\mathrm{d} \sigma_{\eta}} & =\frac{\partial \gamma}{\partial \kappa} \frac{\partial \kappa}{\partial \sigma_{\eta}}+\frac{\partial \gamma}{\partial b_{1}} \frac{\partial b_{1}}{\partial \sigma_{\eta}}+\frac{\partial \gamma}{\partial b_{1}} \frac{\partial b_{1}}{\partial \kappa} \frac{\partial \kappa}{\partial \sigma_{\eta}}
\end{aligned}
$$

Here, the first term on the left hand side of equations 57 and 58 is the direct Jensen's Inequality (J.I.) effect of uncertainty on growth, the second term is the direct timing effect, and the third term reflects the impact of the J.I.-effect on the timing of investment.

What can be said about the signs of these three partial effects of uncertainty on growth? Consider first the J.I.-effect (term 1). Differentiation of 44 with respect to $\kappa$ gives

$$
\frac{\partial \gamma}{\partial \kappa}=\frac{b_{1}\left(\frac{(1-\alpha-\beta)}{(1-\alpha) \alpha}+1\right)-1}{b_{1} s\left(\frac{(1-\alpha-\beta)}{(1-\alpha) \alpha}+1\right)-1}>1
$$

Next, consider the relation between $\kappa$ and $\sigma_{\theta}$ given by 17. The first term of 17 shows that if $\alpha<\frac{1}{2}$, an increase in the uncertainty parameter for quality $\left(\sigma_{\theta}\right)$ will reduce $\kappa$ even if $\mu=0$. The effect of more uncertainty in costs $\left(\sigma_{\eta}\right)$ on $\kappa$ is clearly positive, at least for $\mu \leq 0$. Summarizing, the sign of the direct J.I.-effect is

$$
\begin{aligned}
& \frac{\partial \gamma}{\partial \kappa} \frac{\partial \kappa}{\partial \sigma_{\theta}}\left\{\begin{array}{l}
>0: \alpha>\frac{1}{2} \\
<0: \alpha<\frac{1}{2}
\end{array}\right. \\
& \frac{\partial \gamma}{\partial \kappa} \frac{\partial \kappa}{\partial \sigma_{\eta}}>0 .
\end{aligned}
$$


The direct timing effects are given by the second term of 57 and 58. Differentiation of 44 to $b_{1}$ and setting the result equal to zero yields

$$
0=s \lambda \delta H+(s-1) \kappa+\rho .
$$

The sign of the relation between $\gamma$ and $b_{1}$ depends on the value of $\kappa$

$$
\frac{\partial \gamma}{\partial b_{1}}\left\{\begin{array}{l}
>0: \kappa<\frac{\rho+s \lambda \delta H}{1-s} \\
<0: \kappa>\frac{\rho+s \lambda \delta H}{1-s}
\end{array} .\right.
$$

The direct relations of $b_{1}$ with both $\sigma_{\theta}$ and $\sigma_{\eta}$ are negative as can be seen from 29. The direct timing effects are

$$
\begin{aligned}
& \frac{\partial \gamma}{\partial b_{1}} \frac{\partial b_{1}}{\partial \sigma_{\theta}}\left\{\begin{array}{l}
>0: \kappa>\frac{\rho+s \lambda \delta H}{1-s} \\
<0: \kappa<\frac{\rho+s \lambda \delta H}{1-s}
\end{array}\right. \\
& \frac{\partial \gamma}{\partial b_{1}} \frac{\partial b_{1}}{\partial \sigma_{\eta}}\left\{\begin{array}{l}
>0: \kappa>\frac{\rho+s \lambda \delta H}{1-s} \\
<0: \kappa<\frac{\rho+s \lambda \delta H}{1-s}
\end{array} .\right.
\end{aligned}
$$

Note that if $\kappa=0$, that is, when J.I.-effects are absent, the direct timing effect on growth is negative. Also note that contrary to what can be said of the direct J.I.-effects, both types of uncertainty have an identical impact on timing.

The third term of 57 and 58 represents the impact of J.I.-effects on investment-timing. From the partial derivative of $b_{1}$ with respect to $\kappa$

$$
\frac{\partial b_{1}}{\partial \kappa}=\frac{-1+\kappa\left(\kappa^{2}+2 k^{2}\left(\sigma_{\theta}^{2}+\sigma_{\eta}^{2}-2 \sigma_{\theta} \sigma_{\eta} \mu\right) r\right)^{-\frac{1}{2}}}{k^{2}\left(\sigma_{\theta}^{2}+\sigma_{\eta}^{2}-2 \sigma_{\theta} \sigma_{\eta} \mu\right)}
$$

it is clear that the influence $\kappa$ on $b_{1}$ is negative as

$$
\frac{\kappa}{\sqrt{\kappa^{2}+2 k^{2}\left(\sigma_{\theta}^{2}+\sigma_{\eta}^{2}-2 \sigma_{\theta} \sigma_{\eta} \mu\right) r}}<1 .
$$

Therefore, the impact of uncertainty on growth that runs through both Jensen's Inequality and timing are

$$
\begin{aligned}
& \frac{\partial \gamma}{\partial b_{1}} \frac{\partial b_{1}}{\partial \kappa} \frac{\partial \kappa}{\partial \sigma_{\theta}}\left\{\begin{array}{l}
>0:\left\{\begin{array}{l}
\kappa>\frac{\rho+s \lambda \delta H}{1-s} \& \alpha>\frac{1}{2} \\
\kappa<\frac{\rho+s \lambda \delta H}{1-s} \& \alpha<\frac{1}{2}
\end{array}\right. \\
<0:\left\{\begin{array}{l}
\kappa>\frac{\rho+s \lambda \delta H}{1-s} \& \alpha<\frac{1}{2} \\
\kappa<\frac{\rho+s \lambda \delta H}{1-s} \& \alpha>\frac{1}{2}
\end{array}\right.
\end{array}\right. \\
& \frac{\partial \gamma}{\partial b_{1}} \frac{\partial b_{1}}{\partial \kappa} \frac{\partial \kappa}{\partial \sigma_{\eta}}\left\{\begin{array}{l}
>0: \kappa>\frac{\rho+s \lambda \delta H}{1-s} \\
<0: \kappa<\frac{\rho+s \lambda \delta H}{1-s}
\end{array} .\right.
\end{aligned}
$$




\section{Jensen's Inequality}

As discussed in the introduction, precautionary savings play an important role in the literature on aggregate uncertainty and growth. If fluctuations in the income of individuals can not be insured, precautionary savings may also occur in a setting of micro-uncertainty. If this is the case, uncertainty at the level of the consumer may lead to higher savings rates, and, when capital and knowledge are related, it may even lead to higher long-term growth rates. In this section it is proposed that uncertainty may also change the rate of economic growth in different ways.

Let us start with the general mechanism of which precautionary savings are a special case. The key idea is that the magnitude of uncertainty in one variable is of importance for the level of that variable or another one. First, consider the trivial case of 'biased' uncertainty. For a firm, running the risk of getting an extra order is not the same as running the risk of a warehouse being destroyed by fire. A decrease in the likelihood of fire will certainly raise the profitability of a firm, whereas a decrease in the likelihood of an extra order will not. The probability of a favorable event can be different from the probability of an event that has negative consequences. A rise in uncertainty may change the mean of a variable if uncertainty is biased. Second, whether uncertainty is biased or not may not only depend on the nature of the events but also on the dimension in which it is measured. For example, there is no bias in the outcome of tossing a (fair) coin. The probability of 'head' is equal to that of 'tail'. Now consider that guessing the outcome correctly is rewarded with $\$ 100$ while making a false prediction will only cost $\$ 20$. Accepting uncertainty (tossing the coin) is likely to be more profitable than not accepting uncertainty (no tossing). The outcome measured in pecuniary terms is thus biased while the probability of winning the bet is equal to that of losing it. In other words, the 'upside' of the risk dominates the 'downside' of the risk. Formally, this phenomenon is described by Jensen's Inequality: ${ }^{18}$

If $y$ is a function of the random variable $x$ and $\forall x: y^{\prime \prime}(x) \lessgtr 0$ then $E(y(x)) \lessgtr y(E(x))$.

This effect is illustrated in the graph below. In the graph, $y$ is a concave function of the random variable $x$. The probability that $x$ takes on the value $x^{-}$is $\frac{1}{2}$. The probability that $x$ takes on the value $x^{+}$is also $\frac{1}{2}$. It is easy to see that $y(E(x))>E(y(x))$. From the graph it can also be seen that the magnitude of the difference between $y(E(x))$ and $E(y(x))$ depends on three things. First, the difference will be larger if the function is more concave. Second, the difference between $y(E(x))$ and $E(y(x))$ will be larger if the difference between $x^{-}$and $x$ or between $x^{+}$and $x$ is larger. Third, the probability of $x^{-}$may be different than that of $x^{+}$. Thus, the magnitude of the Jensen's Inequality effect will depend on the concavity (or convexity) of $y(x)$ and on the size and likelihood of deviations from the current value of $x$. If the distribution of $x$ is known, the last two effects are summarized by the effect of the variance of $x$ on Jensen's Inequality.

How is uncertainty related to Jensen's Inequality? There is a discussion about the meaning of uncertainty. In particular, a distinction is made between Knightian uncertainty and risk. Knightian uncertainty implies a total lack of knowledge about the future, whereas risk occurs in

\footnotetext{
${ }^{18}$ In economics, consequences of Jensen's Inequality are commonly referred to as 'second-order effects'.
} 


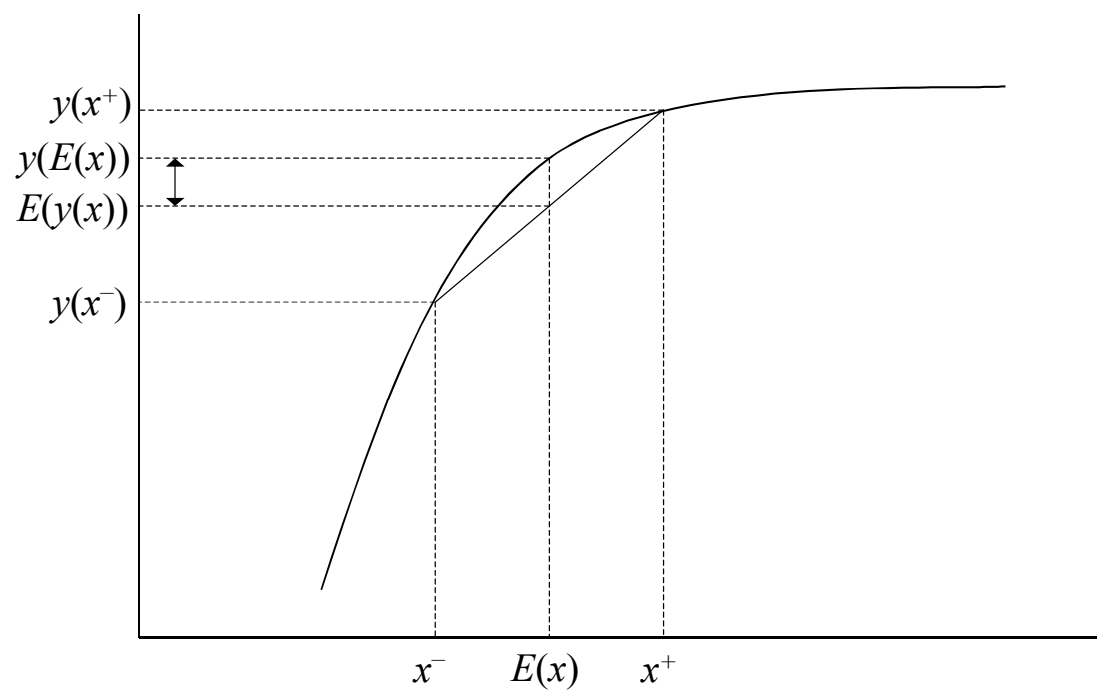

Figure 1: Jensen's Inequality

situations where all possible outcomes and their distribution are known in advance (a discussion of Frank Knight's precise categorization of uncertainty can be found in Runde 1998). The problem with pure Knightian uncertainty is that its magnitude is unmeasurable. Would it be measurable, then at least something would be known about the future. This does not imply that Jensen's Inequality is not relevant in case of Knightian uncertainty. Rather, the magnitude of Jensen's Inequality effects would be unmeasurable. In a situation of pure risk the distribution of outcomes is known in advance and the magnitude of Jensen's Inequality effect can be determined precisely. In reality, individuals will normally be confronted with situations that are somewhere in between the extreme cases of Knightian uncertainty and risk. Nearly always something will be known about possible outcomes and some estimate of their probability can often be made. The literature on 'uncertainty-aversion' argues that the subjectivity of estimates of probability may affect the outcome of decisions. See Schmeidler (1989) for a discussion and Aizenman (1997) for an application to economic development. Of course, subjective-probability effects do not make Jensen's Inequality irrelevant.

The presence of nonlinear relations assures that (unbiased) randomness in one variable will affect the mean and higher moments of the distribution of other variables. As such, it is not difficult to think of uncertainty of some sort to be influencing the mean of any economic variable. Without it being mentioned explicitly, a good amount of results in economics are special cases of Jensen's Inequality. The most famous application of Jensen's Inequality in economics concerns, without a doubt, expected utility. As utility is commonly assumed to be a concave function of 
lifetime consumption, expected utility is a declining function of the variance of consumption. ${ }^{19}$ Bernoulli (1954 (org. 1738), p.24) gave this example:

Somehow a very poor fellow obtains a lottery ticket that will yield with equal probability either nothing or twenty thousand ducats. Will this man evaluate his chance of winning at ten thousand ducats? Would he not be ill-advised to sell this lottery ticket for nine thousand ducats? To me it seems that the answer is in the negative. On the other hand I am inclined to believe that a rich man would be ill-advised to refuse to buy the lottery ticket for nine thousand ducats.

Depending on initial wealth and the interest rate, maximizing expected utility implies that a constant level of consumption is to be preferred to a fluctuating level of consumption, or vice versa. Consumers either engage in precautionary savings in order to smooth their consumption over time, or they consume immediately in order to hedge against an uncertain future. In the model presented in section 4 consumers do not experience uncertainty and therefore neither expected utility effects nor, indeed, risk aversion of any kind is present.

Another special case of Jensen's Inequality can be found in the literature on the flexibility - static-efficiency trade-off. Here, per unit costs are assumed to be a convex function of total production. As a result, the degree of convexity determines how much average costs rise with an increase in production fluctuations. The flexibility - static-efficiency trade-off is established by postulating that minimum average costs are positively related to the convexity of the average cost curve (e.g. Mills and Schumann 1985). Ramey and Ramey (1991) demonstrate a similar mechanism in a general equilibrium context.

\section{References}

Acemoglu, D., and F. Zilibotti (1997): "Was Prometheus Unbound by Chance? Risk, Diversification, and Growth," Journal of Political Economy, 105(4), 709-51.

Aghion, P., And P. Howitt (1992): "A Model of Growth through Creative Destruction," Econometrica, 60(2), 323-51.

Aitchison, J., And J. A. C. Brown (1957): The lognormal distribution, with special reference to its uses in economics. University Press, Cambridge,.

Aizenman, J. (1997): "Investment in New Activities and the Welfare Cost of Uncertainty," Journal of Development Economics, 52(2), 259-77.

Aizenman, J., and N. Marion (1999): "Volatility and Investment: Interpreting Evidence from Developing Countries," Economica, 66(262), 157-79.

Bernoulli, D. (1954 (org. 1738)): "Exposition of a new theory on the measurement of risk (Specimen theoriae novea de mensure sortis)," Econometrica, 22(1), 23-26.

\footnotetext{
${ }^{19} \mathrm{~A}$ critical comment on expected utility theory is given by Rabin and Thaler (2001)
} 
Bertola, G. (1994): "Flexibility, Investment, and Growth," Journal of Monetary Economics, $34(2), 215-38$.

Brock, W. A., and L. J. Mirman (1972): "Optimal Economic Growth and Uncertainty: The Discounted Case," Journal of Economic Theory, 4(3), 479-513.

Caporale, T., and B. McKiernan (1996): "The Relationship between Output Variability and Growth: Evidence from Post War UK Data," Scottish Journal of Political Economy, 43(2), 229-36.

(1998): "The Fischer Black Hypothesis: Some Time-Series Evidence," Southern Economic Journal, 64(3), 765-71.

Carruth, A., A. Dickerson, and A. Henley (2000): "What Do We Know about Investment under Uncertainty?," Journal of Economic Surveys, 14(2), 119-53.

DE HEK, P. A. (1999): "On Endogenous Growth under Uncertainty," International Economic Review, 40(3), 727-44.

Dixit, A. K. (1993): The art of smooth pasting. Harwood Academic Publishers, Chur, Switzerland.

Dixit, A. K., And R. S. PIndyck (1994): Investment under uncertainty. Princeton University Press, Princeton.

Goel, R. K., And R. RAm (2001): "Irreversibility of R\&D investment and the adverse effect of uncertainty: Evidence from the OECD countries," Economics Letters, 71(2), 287-291.

Greenwood, J., And B. Jovanovic (1990): "Financial Development, Growth, and the Distribution of Income," Journal of Political Economy, 98(5), 1990, pages 1076-1107.

Grier, K. B., And G. Tullock (1989): "An Empirical Analysis of Cross-National Economic Growth, 1951-80," Journal of Monetary Economics, 24(2), 259-76.

Grossman, G. M., and E. Helpman (1991): "Quality Ladders in the Theory of Growth," Review of Economic Studies, 58(1), 43-61.

Jones, L. E., R. E. Manuelli, and E. Stacchetti (1999): Technology (and policy) shocks in models of endogenous growth. NBER Working Paper 7063.

Kormendi, R. C., and P. G. Meguire (1985): "Macroeconomic Determinants of Growth: Cross-Country Evidence," Journal of Monetary Economics, 16(2), 141-63.

Levhari, D., and T. N. Srinivasan (1969): "Optimal Savings under Uncertainty," Review of Economic Studies, 36(106), 153-63.

Lucas, Robert E., J. (1988): "On the Mechanics of Economic Development," Journal of Monetary Economics, 22(1), 3-42. 
Malliaris, A. G., And W. A. Brock (1982): Stochastic methods in economics and finance. North-Holland, New York.

Mills, D. E., And L. Schumann (1985): "Industry Structure with Fluctuating Demand," American Economic Review, 75(4), 758-67.

Mirman, L. J. (1971): "Uncertainty and Optimal Consumption Decisions," Econometrica, $39(1), 179-85$.

Phelps, E. (1962): "The accumulation of risky capital: A sequential utility analysis," Econometrica, 30, 729-743.

Rabin, M., and R. H. Thaler (2001): "Anomalies: Risk Aversion," Journal of Economic Perspectives, 15(1), 219-32.

Ramey, G., And V. A. Ramey (1991): Technology Commitment and the Cost of Economic Fluctuations. NBER Working Paper 3755.

(1995): "Cross-Country Evidence on the Link between Volatility and Growth," American Economic Review, 85(5), 1138-51.

Romer, P. M. (1986): "Increasing Returns and Long-run Growth," Journal of Political Economy, 94(5), 1002-37. S71-S102.

Rothschild, M., and J. E. Stiglitz (1971): "Increasing Risk II: Its Economic Consequences," Journal of Economic Theory, 3(1), 66-84.

Runde, J. (1998): "Clarifying Frank Knight's Discussion of the Meaning of Risk and Uncertainty," Cambridge Journal of Economics, 22(5), 539-46.

SchmeIdler, D. (1989): "Subjective Probability and Expected Utility without Additivity," Econometrica, 57(3), 571-87.

Zon, A. V., H. MeiJers, And I. H. Yetkiner (1999): "Endogenous energy saving technical change in the Romer model," MERIT Research Memorandum, (2/99-022). 